\title{
A new look at discontinuous respiration in pupae of Hyalophora cecropia (Lepidoptera: Saturniidae): Haemocoelic pressure, extracardiac pulsations and $\mathrm{O}_{2}$ consumption*
}

\author{
KAREL SLÁMA \\ Institute of Entomology, Biology Centre of Czech Academy of Sciences, Drnovská 507, 16100 Praha 6, Czech Republic; \\ e-mail: slama@entu.cas.cz
}

Key words. Saturniidae, Hyalophora cecropia, respiratory acidaemia, haemocoelic pulsations, respiratory movements, $\mathrm{O}_{2}$ consumption, spiracular pulsations, $\mathrm{CO}_{2}$ bursts, chemically produced $\mathrm{CO}_{2}$, carbonic anhydrase

\begin{abstract}
Discontinuous respiration in diapausing pupae of Cecropia silkworms was monitored by means of several electronic methods, including recording changes in haemocoelic pressure, monitoring respiratory movements by strain-gauge sensors and nanorespirographic recording of $\mathrm{O}_{2}$ consumption and $\mathrm{CO}_{2}$ output. It appears that, in contrast to previous concepts of stereotypic discontinuous respiration cycles (DGC) driven by accumulation of gaseous $\mathrm{CO}_{2}$ in the body, the new results indicate that $\mathrm{CO}_{2}$ remains dissolved in liquid carbonate buffers during interburst periods. In other words, there is no accumulation of gaseous $\mathrm{CO}_{2}$ within the air filled tracheal space between the bursts. The bursts of $\mathrm{CO}_{2}$ are caused by homeostatically regulated enzymatic hydration by carbonic anhydrase of metabolically produced carbonic acid. The chemically produced gaseous $\mathrm{CO}_{2}$ was exhaled mainly by a bulk outflow through selectively opened or pulsating spiracles. The output of $\mathrm{CO}_{2}$ was enhanced by actively regulated, unidirectional ventilation. The deep depressions in haemocoelic pressure, caused by permanent closure of all spiracular valves for long periods, appeared to be a specific feature of diapausing saturniid pupae. Physiologically, it has circulatory, not respiratory functions. The original definition of spiracular "fluttering" resulted from a misinterpretation of previously unknown extracardiac pulsations in haemocoelic pressure. The coordinated pulsation of the spiracular valves with extracardiac pulsations produce a very efficient, unidirectional ventilation of the whole tracheal system. According to the new results, the discontinuous respiration cycles of diapausing Cecropia pupae can be briefly described as follows: (1) Spiracular valves are kept permanently closed during the periods of deep depressions, they remain closed for some $99 \%$ of the time with occasional snap opening (passive inspirations) during prolonged interburst periods and more than 50\% closed during the bursts; (2) During the long interburst periods, $\mathrm{CO}_{2}$ is retained in liquid carbonate buffers, while the relatively high (after the burst) or low (toward the next burst) rate of $\mathrm{O}_{2}$ consumption creates an internal vacuum, which is homeostatically compensated for by the snap-opening of one or just a few spiracular valves (passive suction inspirations); (3) The $\mathrm{CO}_{2}$ gas, produced enzymatically by carbonic anhydrase, enters the air filled tracheal system and leaves the body by diffusion, a bulk outflow, or actively regulated unidirectional ventilation ("fluttering" spiracles). The selective advantage of this actively regulated respiratory system for water retention in pupae is discussed.
\end{abstract}

\section{INTRODUCTION}

Investigations of the discontinuous $\mathrm{CO}_{2}$ release by insects were a common topic of many papers and review articles some four decades ago (Schneiderman \& Williams, 1955; Schneiderman, 1960; Sláma, 1960; Buck, 1962; Levy \& Schneiderman, 1966a, b, c). The studies were mostly made on giant diapausing pupae of the Cecropia silkworm. Unfortunately, these excellent studies on Cecropia were discontinued in 1974 (Burkett \& Schneiderman, 1974a, b) and since that time no new experimental data on discontinuous respiration in diapausing pupae published. Old problems thus remained unresolved and in certain cases even misinterpreted in the numerous review articles that followed (see below). Schneiderman's original concept of discontinuous respiration was based on Krogh's (1920) diffusion theory, which claimed that the respiration of immobile insects was regulated by a simple, passive diffusion of $\mathrm{O}_{2}$ and $\mathrm{CO}_{2}$ through the spiracles, without the need for respiratory movements and active ventilation. Accordingly, these discontinuous respiration cycles were assumed to be caused by the mechanical opening or closing of the spiracular valves triggered by the composition of intratracheal gas (Schneiderman, 1960; Schneiderman \& Schechter, 1966; Levy \& Schneiderman, 1966a, b, c; Brockway \& Schneiderman, 1967). Krogh's illusive concept led Schneiderman and his co-workers (see Schneiderman, 1960; Levy \& Schneiderman, 1966a, b, c) to develop a theory of stereotypic, 3-phasic DGC (discontinuous gas cycles) or OCF cycles ( $\mathrm{O}$ for open, $\mathrm{C}$ for closed and $\mathrm{F}$ for fluttering spiracles) by later authors (Kestler, 1985; Lighton, 1996; Chown et al., 2006; Quinlan \& Gibbs, 2006). According to these mechanistic DGC or OCF concepts, gaseous $\mathrm{CO}_{2}$ should continuously

\footnotetext{
* This work is dedicated to the memory of the late Prof. H.A. Schneiderman for his pioneering work on discontinuous respiration cycles in insects. Prof. Schneiderman was awarded the Gregor Mendel gold medal by the Czechoslovak Academy of Sciences in 1990. His extensive reprint collection on insect respiration was kindly donated to the Institute of Entomology, Czech Academy of Sciences in České Budějovice by Mme Audrey Schneiderman.
} 
accumulate within the closed tracheal system until its concentration reached about 6.4\% (Levy \& Schneiderman, 1958, 1966a; Schneiderman, 1960). The high concentration of $\mathrm{CO}_{2}$ then caused the spiracular valves to open and let the accumulated $\mathrm{CO}_{2}$ diffuse out through the widely open spiracles (see reviews by Buck, 1962; Brockway \& Schneiderman, 1967; Burkett \& Schneiderman, 1974b; Miller, 1981; Kestler, 1985; Lighton, 1996; Wasserthal, 1996).

More recent reviews on the discontinuous respiration of insects (for references see Chown et al., 2006; Quinlan \& Gibbs, 2006; Contreras \& Bradley, 2009) still adhere fully to the mechanistic, 85-year-old diffusion theory of Krogh (1920). They completely ignore the existence of ventilatory movements, neglect the programmed nervous operation of the spiracular valves (note that internal gas concentrations change within intervals of many minutes, while spiracular valves open and close in milliseconds) and claim that the discontinuous bursts of $\mathrm{CO}_{2}$ are only due to the passive, physical diffusion of the accumulated $\mathrm{CO}_{2}$ through open spiracles. Several speculative theories about the possible origin and evolution of the stereotypic DGC or OCF respiration cycles were proposed (Chown et al., 2006), ignoring the possibility that insect breathing could be actively regulated by the neuroendocrine system, including extracardiac pulsations, ventilatory movements and chemically produced liberation of $\mathrm{CO}_{2}$ from carbonate buffers (Sláma, 1988, 1999, 2001a, 2009; Sláma et al., 2007).

In their original observations on discontinuous respiration cycles in Cecropia, Schneiderman and his co-workers also denied the presence of active respiratory movements, except those of the spiracular valves (Levy \& Schneiderman, 1966a). They found that the valves of the abdominal spiracles occasionally "fluttered" 16 - to 22 -times per min. The spiracular "fluttering" was observed and described many times (Schneiderman, 1956, 1960; Levy \& Schneiderman, 1958, 1966a) and evidence of it was also present in graphical recordings (Schneiderman, 1960). However, its physiological function was never sufficiently explained. In the last papers on discontinuous respiration in Cecropia, Schneiderman and his co-workers substantially changed the definition of spiracular "fluttering". The meaning of "fluttering spiracles" was redefined as the period during which "the valves continuously open briefly and then close for several minutes" (Brockway \& Schneiderman, 1967; Burkett \& Schneiderman, 1974a, b). Apparently, the new definition of "fluttering" abandoned the original, 16- to 22-per min movements of the valves (Schneiderman, 1960) and re-assigned the term "fluttering" to the brief openings of the valves during the whole period of passive inspirations. After 1974, the confusion associated with the mechanical DGC and spiracular "fluttering" became the most controversial feature of discontinuous respiration in insects (Lighton, 1996; Chown et al., 2006; Sláma et al., 2007; Contreras \& Bradley, 2009). This statement is well documented by the conservative descriptions of DGC in recently used textbooks on insect physiology (Nation, 2002; Klowden, 2007). Thus, in order to shed some new light on this problem, the respiratory physiology of diapausing Cecropia pupae was systematically reinvestigated, using recently available electronic techniques. In this introductory paper the new results are compared with data that is half a century old and still used to account for discontinuous respiration in insects. The work was facilitated by reviewing the extensive collection of original reprints of old papers.

\section{MATERIAL AND METHODS}

The pupae of Hyalophora cecropia (Lepidoptera: Saturniidae) were obtained by rearing the larvae indoors on fresh twigs cut from various fruit trees, mainly apples. The material was occasionally refreshed by eggs obtained from various sources in the US. Generally, two kinds of pupae were used in the experiments: (a) Unchilled diapausing pupae stored and measured at room temperature within one year, and (b) Chilled pupae stored at $+5^{\circ}$ for several months up to 2 years, which were brought to room temperature and measured during various stages of the post diapause development. Most of the work was done from 1966 to 2009, with some interruptions caused by a lack of material. According to the database, the majority of the prolonged, multichannel recordings of various physiological functions in diapausing pupae of Cecropia were made during the years 1998-2000 $(n=90), 1983-1994$ (75), 1981-83 (52), 1976-80 (26) and 2007-2009 (103).

The recording methods involved a combination of several electronic techniques: (1) The technique for recording insect "blood" pressure was developed for the continuous monitoring of extracardiac and cardiac pulsations in pupal haemocoelic pressure (Sláma, 1976, 1984a, 2008); (2) The strain-gauge technique was used for the prolonged monitoring of microscopic respiratory movements and also for the indirect recording of haemocoelic pressure pulses from the body surface (Sláma, 1984a, 2000a; Sláma \& Neven, 2001); (3) The thermographic technique was used for recording heartbeat and estimating the subepidermal flow of haemolymph (Sláma, 2000a, 2003, 2010); (4) The scanning microrespirographic technique was employed for the monitoring $\mathrm{O}_{2}$ consumption and $\mathrm{CO}_{2}$ output in picoliter quantities per minute (Sláma, 1984b; Sláma \& Denlinger, 1992; Sláma \& Neven, 2001; Sláma et al., 2007). The multichannel output signals were originally recorded on linear recorders, later on a PC using DATAQ (Columbus, $\mathrm{OH}$ ) hardware and software.

The results retrieved from the database were subjected to individual evaluation and processing. There was no average pupa with regard to respiratory cycles. The research was purely qualitative, based on a large number of variable individual values. Except for a few cases, this rendered averages and statistical evaluations superfluous. The records were thoroughly evaluated and the numbers $(n)$ of pupae used for each experimental group are given in the text or in Figure captions. In this summarising paper only a few selected, more or less representative records for a given experimental group and technical design are shown.

\section{RESULTS}

\section{Haemocoelic pressure in diapausing Cecropia pupae}

The nonfeeding, immobile metamorphosic stages of insects have a rather constant surface to volume ratio, which is proportional to internal (haemocoelic) body pressure. Immobile prepupae of Cecropia removed from the cocoon already show pupal type physiological regulations. This is manifested by the appearance of heartbeat 

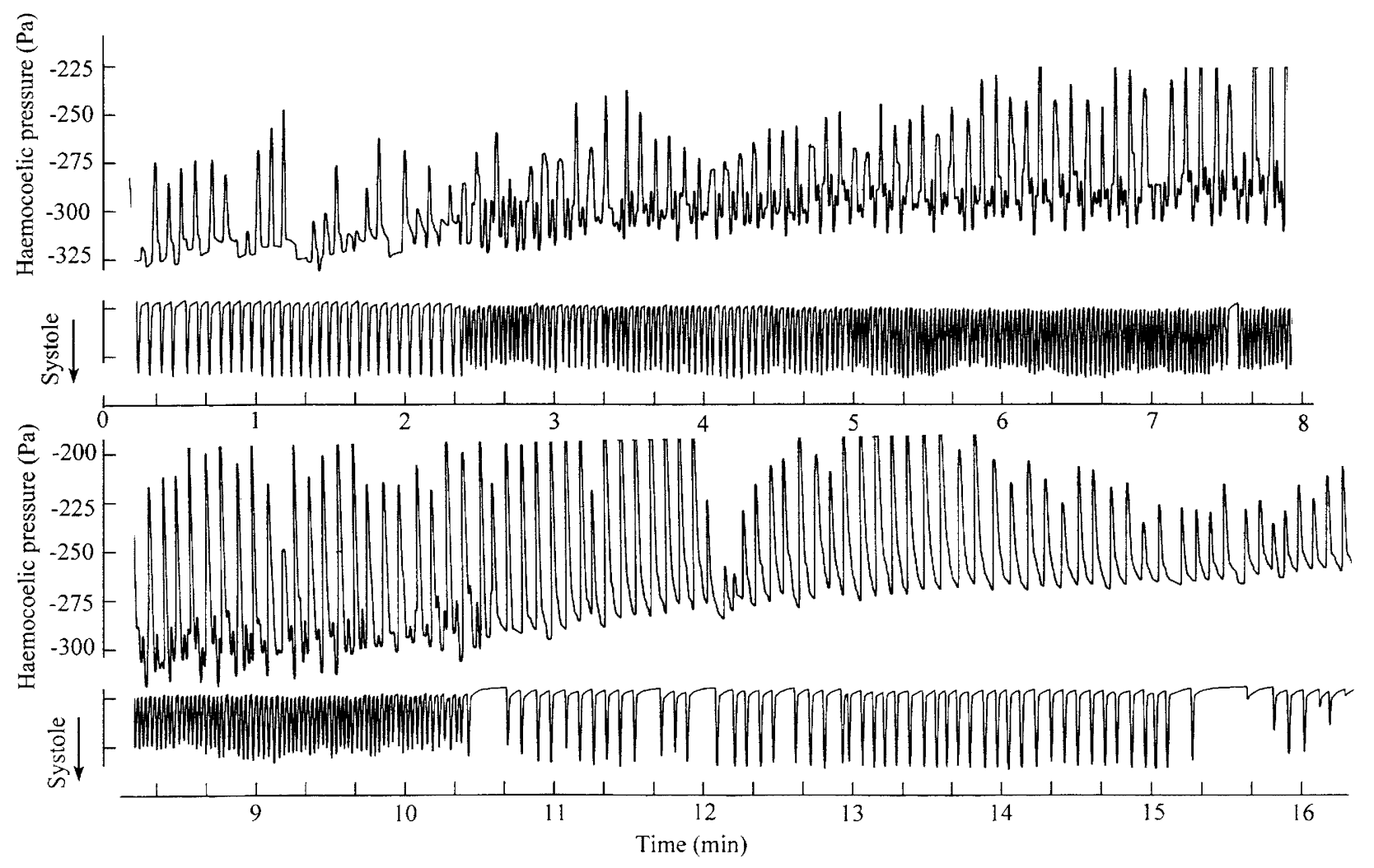

Fig. 1. Extracardiac pulsations in haemocoelic pressure recorded by a hydraulic transducer connected to the body cavity (upper records) and simultaneously recorded heartbeat of an immobile prepupal stage $(5.5 \mathrm{~g}), 4$ days after spinning the $\operatorname{cocoon}\left(22^{\circ} \mathrm{C}\right)$. The heartbeat record was obtained by simple visual observation and mechanical recording of the systolic contractions by pressing an electrical switch.

reversal, frequent extracardiac pulsations in haemocoelic pressure and the discontinuous release of $\mathrm{CO}_{2}$. The prediapause, prepupal physiological changes are not going to be described in more detail here, except for the records in Fig. 1, which show the relationship between extracardiac haemocoelic pulsations and heartbeat. The records of systolic contractions of the heart (lower traces) clearly show alternations in the faster, forward directed (anterograde) and the reciprocal (retrograde) peristaltic waves of the heart. The effect of heartbeat on blood pressure was evidently much smaller than that of the extracardiac pulsations (originally described as "fluttering") caused by the co-ordinated contractions of the muscular body sheath.
The actively regulated ventilatory movements associated with extracardiac pulsations culminated during pupal ecdysis, then faded during the hardening of the pupal cuticle, when the blood pressure slowly decreased to subatmospheric values. Two days after ecdysis, the pupae with hardened integuments started to tightly seal all spiracular valves for a few minutes. This special case of permanent closure of all spiracular valves resulted in the formation of a temporary vacuum created by the continuous $\mathrm{O}_{2}$ consumption of the tissues and organs. After some 10 or $20 \mathrm{~min}$ the vacuum was periodically broken by the snap-opening of one or a few selected spiracles, which was immediately followed by a gulp inflow of

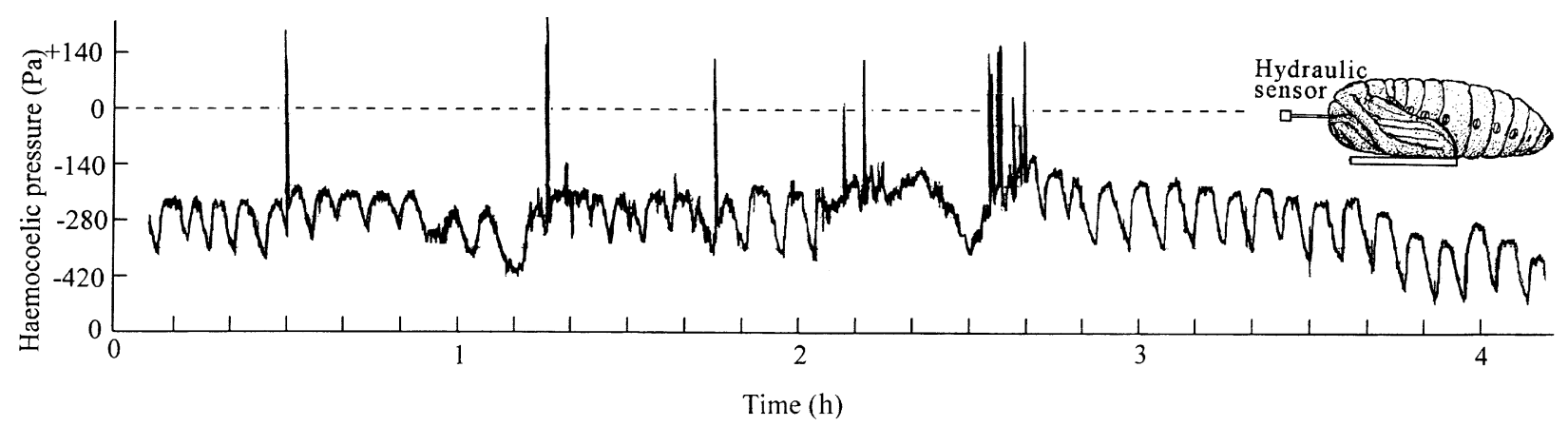

Fig. 2. Saw-tooth pattern in subatmospheric haemocoelic pressure showing passive inspirations of air every 5 to 6 min by a pupa $(4.2 \mathrm{~g})$ at the beginning of pharate adult development $\left(23^{\circ} \mathrm{C}\right)$. Broken line indicates atmospheric zero pressure, the peaks show large ventilatory expirations. 


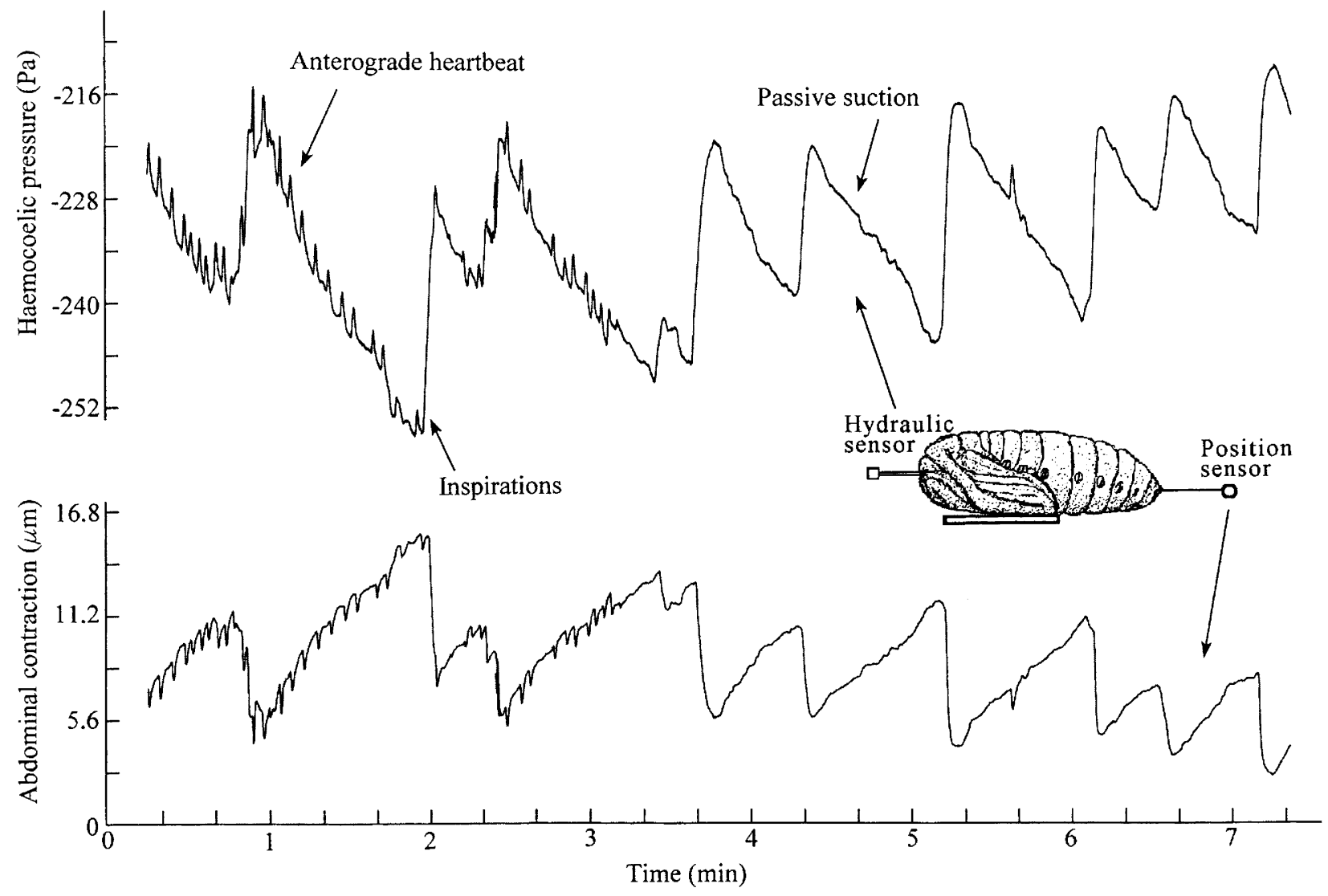

Fig. 3. Simultaneous recordings of haemocoelic pressure (above) and telescopic contractions of the abdomen showing saw-tooth pattern and mirror image relationships between haemocoelic pressure and abdominal contractions during an interburst period of a diapausing pupa $(3.4 \mathrm{~g})$ at $23^{\circ} \mathrm{C}$. The more or less constant ratio between haemocoelic pressure and abdominal contraction (passive suction) is $16 \mathrm{~Pa} / \mathrm{min}=8 \mu \mathrm{m} / \mathrm{min}$, respectively.

fresh air. This type of "saw-tooth" pattern in haemocoelic pressure (see Fig. 2) is the most common feature of the prolonged interburst period. Anemometric measurements of the passage of air through individual spiracles (to be published elsewhere) revealed that the speed and size of the individual inspirations were directly proportional to the degree of vacuum created and were indirectly proportional to the number of simultaneously opened spiracles. The record of the "saw-tooth" respiratory pattern in haemocoelic pressure in Fig. 2 was obtained from a developing pupa whose passive inspirations occasionally alternated with active expirations of air (large upward peaks in pressure).

The saw-tooth pattern of changes in haemocoelic pressure is the most common, essential feature of all diapausing and early post diapause pupae. It is recorded during a substantial part of discontinuous respiration cycles, except for relatively short periods during the $\mathrm{CO}_{2}$ bursts (15-20 min duration with periodicity of $5 \mathrm{~h}$ to 16 h) and the periods when the spiracles are permanently closed after each burst. In contrast to the more or less obligatory saw-tooth pattern of inspirations, the large depressions in haemocoelic pressure (permanently sealed spiracles) occur in certain specimens only sporadically or are not recorded for long periods of time.
The direct recording of blood pressure patterns from the haemocoele involves penetration of the integument with measuring needles, which often get clogged by coagulating haemolymph. Thus an elegant, indirect, non invasive method was developed for recording changes in pupal haemocoelic pressure from the body surface. The method is based on the more or less constant surface/volume pupal ratios. "Posimetric", strain-gauge electronic transducers were used to record the relative changes in haemocoelic pressure by measuring the movement of flexible integumental areas, such as the wing lobes, or flexible abdominal segments.

Fig. 3 shows the characteristic, mirror image pattern of simultaneously recorded blood pressure and abdominal movements. In principle, a decrease in internal pressure causes a proportional telescopic contraction of the terminal abdominal segments. These records are very instructive. For example, a small fraction of the record in Fig. 3 revealed the exact interval of inspirations (1-2 per $\mathrm{min}$ ), the duration of the snap-opening of actively working spiracles $(0.25-0.35 \mathrm{~s})$ as well as the rate of vacuum formation within the pupal body. Moreover, the records can also reveal the frequency $(14 / \mathrm{min})$ and amplitude ( $1 \mu \mathrm{m}$ or $2 \mathrm{~Pa}$ in pressure) of the heartbeat (see 0 to 3 min of the recording time). As far as the period of pupal diapause is concerned, the most important physiological 

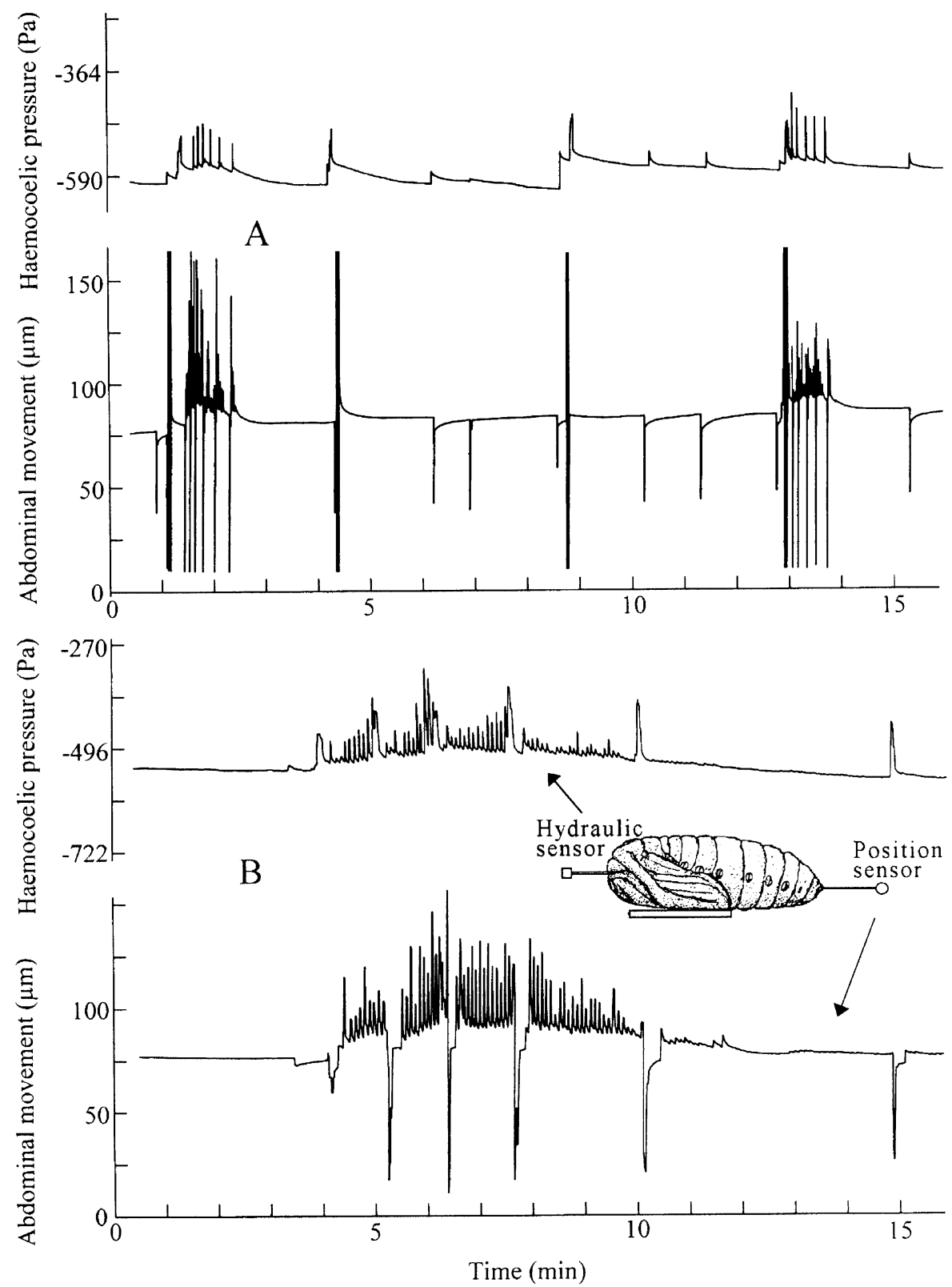

Fig. 4. Synchronized records of "blood" pressure (upper traces) and telescopic contractions of the tip of abdomen of a pupa (3.8 g) at the end of diapause $\left(20^{\circ} \mathrm{C}\right)$. showing occasional ventilatory movements in A and extracardiac pulsation in "blood" pressure in B. The ratio between movements of the tip of the abdomen and blood pressure is: $1 \mu \mathrm{m}=2.2 \mathrm{~Pa}$, respectively.

measure is the velocity of pressure decrease (vacuum formation) expressed per unit time. This measure is indicated by the corresponding contraction of the flexible, 5th to 7 th abdominal segments. For the pupa measured in Fig. 3 these segments contracted at a more or less constant rate of $8 \mu \mathrm{m}$ per minute and this corresponds to an internal pressure decrease of $16 \mathrm{~Pa}$ per min. The constant ratio between decreasing internal pressure and contraction of abdominal segments for the pupa in Fig. 3 shows that a $3.1 \mu \mathrm{m}$ of abdominal contraction is equivalent to an increase of $2 \mathrm{~Pa}$ in negative pressure. This ratio appeared to be rather constant for pupae of equal size, sex and developmental state. The direct proportion between the ratio and $\mathrm{O}_{2}$ consumption suggests that it may be used as an important metabolic measure for determining the physiological state of pupae (diapause, early post diapause, pharate adult development). Finally, the records in Fig. 3 show that the pupa snap-opened the determined spiracle for $250 \mathrm{~ms}, 10$ times during $7 \mathrm{~min}$ of the recording period. This shows that during the interburst period the spiracles could be tightly closed for some $99 \%$ of the time.

Further recordings, using a similar experimental design to that shown in Fig. 3, provided statistical data for several dozens of Cecropia pupae at different stages of diapause and development. The ratio between abdominal contraction and haemocoelic pressure was close to $1 \mu \mathrm{m}$ $=2.23 \mathrm{~Pa}$ (S.D. $=0.3 \mathrm{~Pa}, n=16$ ) for small pupae (3.5 to 4 g, usually males) or $1 \mu \mathrm{m}=1.56 \mathrm{~Pa}$ (S.D. $=0.4 \mathrm{~Pa}, \mathrm{n}=$ 19) for large pupae ( $5.5 \mathrm{~g}$ and more). When certain spira- 


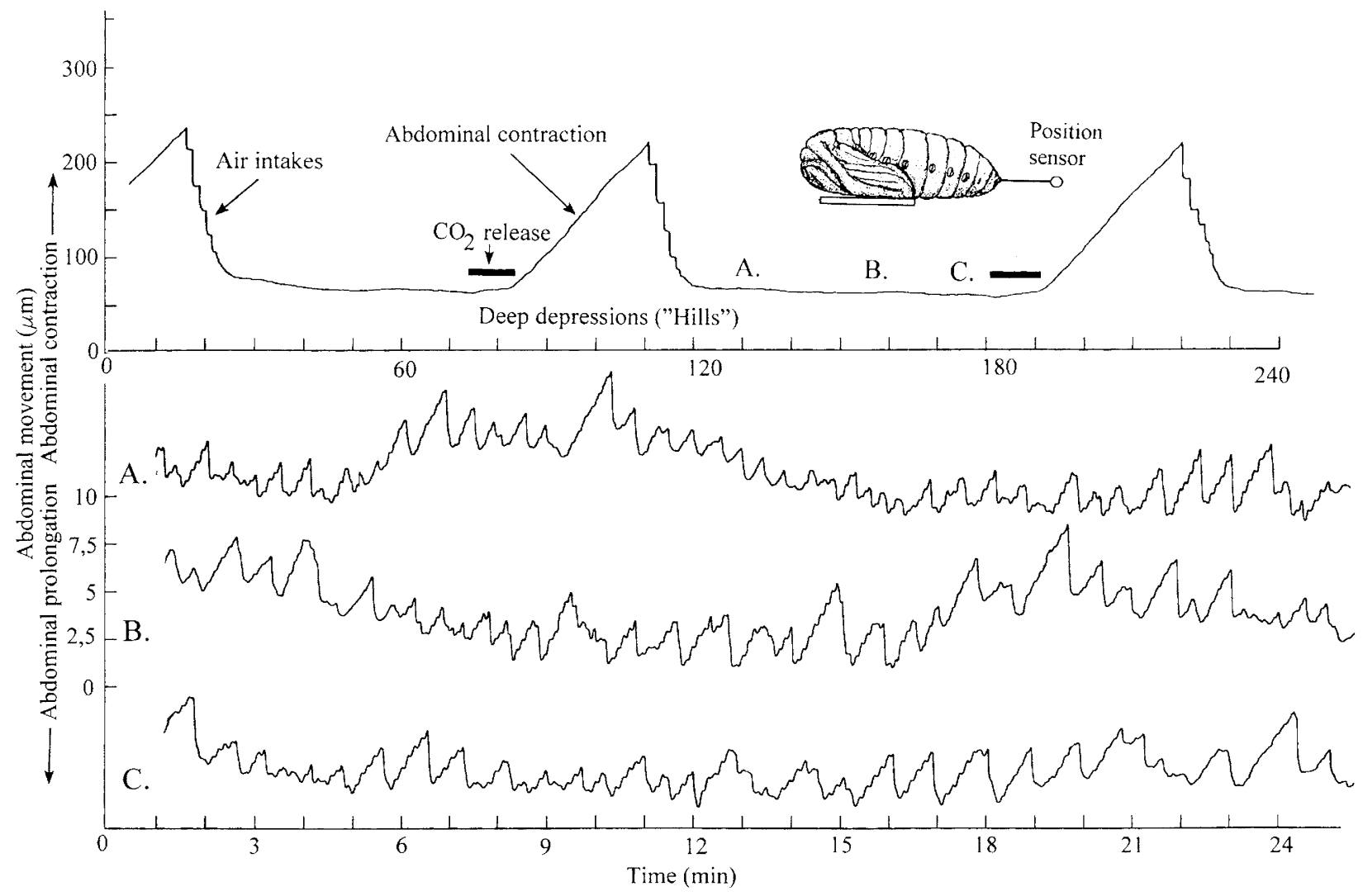

Fig. 5. Relative changes in haemocoelic pressure recorded by a position sensor on the tip of the abdomen of $3.4 \mathrm{~g}$ pupa at the beginning of diapause (upper record; 10 days from pupal ecdysis; $2 \mathrm{~h}$ periodicity of $\mathrm{CO}_{2}$ bursts at $23^{\circ} \mathrm{C}$. The deep depressions in haemocoelic pressure after each $\mathrm{CO}_{2}$ burst appear as reciprocal "hills" (mirror image of changes in haemocoelic pressure). The "hills" are terminated by multiple intakes of air. Duration of $\mathrm{CO}_{2}$ bursts was interpolated from direct $\mathrm{CO}_{2}$ measurements on the same pupa (not shown here). Lower records show a more detailed saw-tooth pattern of inspirations at the beginning (A), in the middle (B) and at the end $(\mathrm{C})$ of an interburst period. The constant rate of abdominal contraction (passive suction) was $3.75 \mu \mathrm{m} / \mathrm{min}$.

cles opened for a longer period of one second (which was usually the case during $\mathrm{CO}_{2}$ bursts), haemocoelic pressure oscillated around the atmospheric zero level. In this case the described proportionality between abdominal movements and internal pressure ceased to exist. The isometric/anisotonic physical conditions of the closed pupa suddenly changed into an isotonic/anisometric state. The effect of abdominal movements on blood pressure became attenuated or buffered by the inflow or outflow of air through the open spiracles (punctured ball effect). The data in Fig. 4 show, however, that during large individual inspirations or expirations (upper records), or during extracardiac pulsations (lower records), the effect of abdominal ventilatory movements on haemocoelic pressure is relatively small, but can be discerned. During the extracardiac pulsation in Fig. 4B (below), the ratio between adominal movement and haemocoelic pressure was $1 \mu \mathrm{m}=2.2 \mathrm{~Pa}$, similar to that recorded for the pupa measured in Fig. 3.

\section{Recording of haemocoelic pressure from the body surface}

Because of the constant ratio between abdominal contraction and haemocoelic pressure (see Fig. 3) it is possible to obtain essential data on internal pressure by simple recordings changes in the length of the abdomen.
This method enabled repeated measurements to be made on unrestrained pupae throughout the whole period of diapause. The records in Fig. 5 indicate that the measures obtained from the tip of the abdomen are also very practical. Although they show only an inverted mirror image of the changes in haemocoelic pressure, they accurately reproduce the velocity of vacuum formation, intervals of inspirations, periods of extracardiac pulsations and deep depressions in internal volume.

The pupae of Cecropia, like most lepidopteran pupae, have three elastic intersegmental membranes between abdominal segments 4 and 7. Between these segments there are very large bundles of intersegmental muscles, which can contract the segments telescopically into each other, thus functioning as an efficient, bellows-like abdominal pressure pump. In an emergency, the pumping movements of these segments can quickly replace the air in the entire tracheal space with fresh air within just a few seconds. This type of actively regulated ventilation of the tracheal system occurs at the beginning and end of the U-shaped pupal metabolic curve. When at the bottom of the U-shaped metabolic curve, the rate of $\mathrm{O}_{2}$ consumption falls to some $5-20 \mu \mathrm{l} / \mathrm{g} / \mathrm{h}$. At this low level of respiratory metabolism there is no need for extensive ventilation and a pupa can remain sealed from outside for many hours. The demands for oxygen are covered from internal 

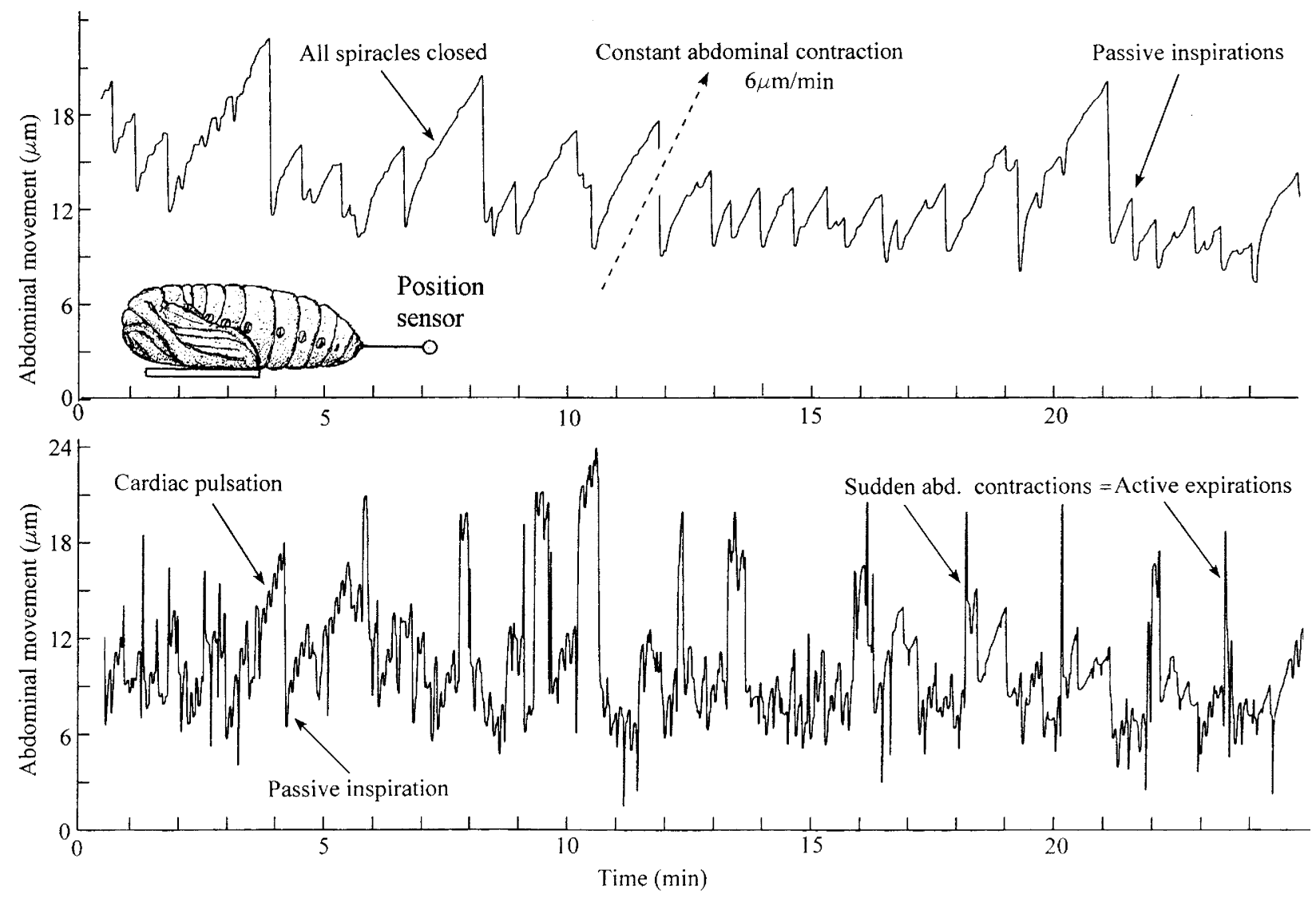

Fig. 6. The saw- tooth pattern of inspirations (above) during diapause of a $5.6 \mathrm{~g}$ pupa $\left(6-8 \mathrm{~h}\right.$ periodicity of $\mathrm{CO}_{2}$ bursts; $20^{\circ} \mathrm{C}$ with a constant rate of abdominal contraction $6 \mu \mathrm{m} / \mathrm{min}$; at $20^{\circ} \mathrm{C}$. Lower record shows abdominal contractions of the same pupa during pharate adult development recorded several weeks later at $23^{\circ} \mathrm{C}$.

resources of air contained in the tracheal system and in the subalar air cavity. In addition, oxygen is periodically replenished by passive inspirations of fresh air. The selective advantage of this respiratory mechanism for pupal survival obviously relates to the ability to prevent almost $100 \%$ of respiratory water loss.

The upper record in Fig. 5 shows the most common, low sensitivity, graphic illustration of the mechanical changes associated with discontinuous $\mathrm{CO}_{2}$ release. There are 2 complete respiratory cycles characterized by relatively short bursts of $\mathrm{CO}_{2}$, which are immediately followed by the closure of all spiracular valves, which results in a deep decline in haemocoelic pressure. Position sensors show these deep depressions as a large contraction of the terminal abdominal segments, which is a mirror image of the actual pressure decline and appear on the records as "hills". As already mentioned, large abdominal contractions ("hills") are caused by the tight sealing of all spiracular valves for about $30 \mathrm{~min}$. During this time, haemocoelic pressure steadily decreases down to subatmospheric levels due to the consumption of oxygen, whose reduced partial pressure is still sufficient to cover the extremely small metabolic demands of diapausing tissues. The formation of the internal vacuum is enhanced by the retention of the metabolically produced $\mathrm{CO}_{2}$ in the liquid form of carbonate buffers.

The delicate mechanical changes in the pupal body during the prolonged interburst periods is illustrated by the lower records in Fig. 5. They can be briefly explained as follows: (1) Spiracular valves of the pupa are closed most of the time, which is clearly indicated by a constant rate of abdominal contraction (vacuum formation); (2) At determined intervals (about 1 min in Fig. 5), specific spiracular valves intermittently snap-open for about $250 \mathrm{~ms}$, which is followed by a sudden gulp of air, thus causing a sudden extension of the abdominal segments (indicating an increase in internal pressure); (3) During large "hills" or deep depressions following $\mathrm{CO}_{2}$ bursts, all spiracular valves are permanently sealed for some 25 to $40 \mathrm{~min}$, which results in a deep decrease in internal pressure to subatmospheric values of $-1 \mathrm{kPa}$ or more (occasionally up to $-4 \mathrm{kPa}$ ); (4) The "hills" are terminated by a flashopening of certain spiracular valves, mostly the prothoracic ones, which twinkle for 100 to $500 \mathrm{~ms}$ once or twice per minute; (5) Each flash-opening of the valves produces a rapid convective inflow of fresh air into the body, the speed of which is directly proportional to the extant value of the internal vacuum; (6) The convective influx of air terminating the "hills" is strong enough to rule out a possibility of a countercurrent diffusion of internal gas or escape of water vapour; (7) There is no accumulation of gaseous $\mathrm{CO}_{2}$ within the tracheal system between the two $\mathrm{CO}_{2}$ bursts (internal gas forcibly expired after mechanical irritation did not contain elevated levels of $\mathrm{CO}_{2}$ ) and; (8) The occurrence of extracardiac haemocoelic pulsations ("fluttering"), which is common in prediapause, postdia- 


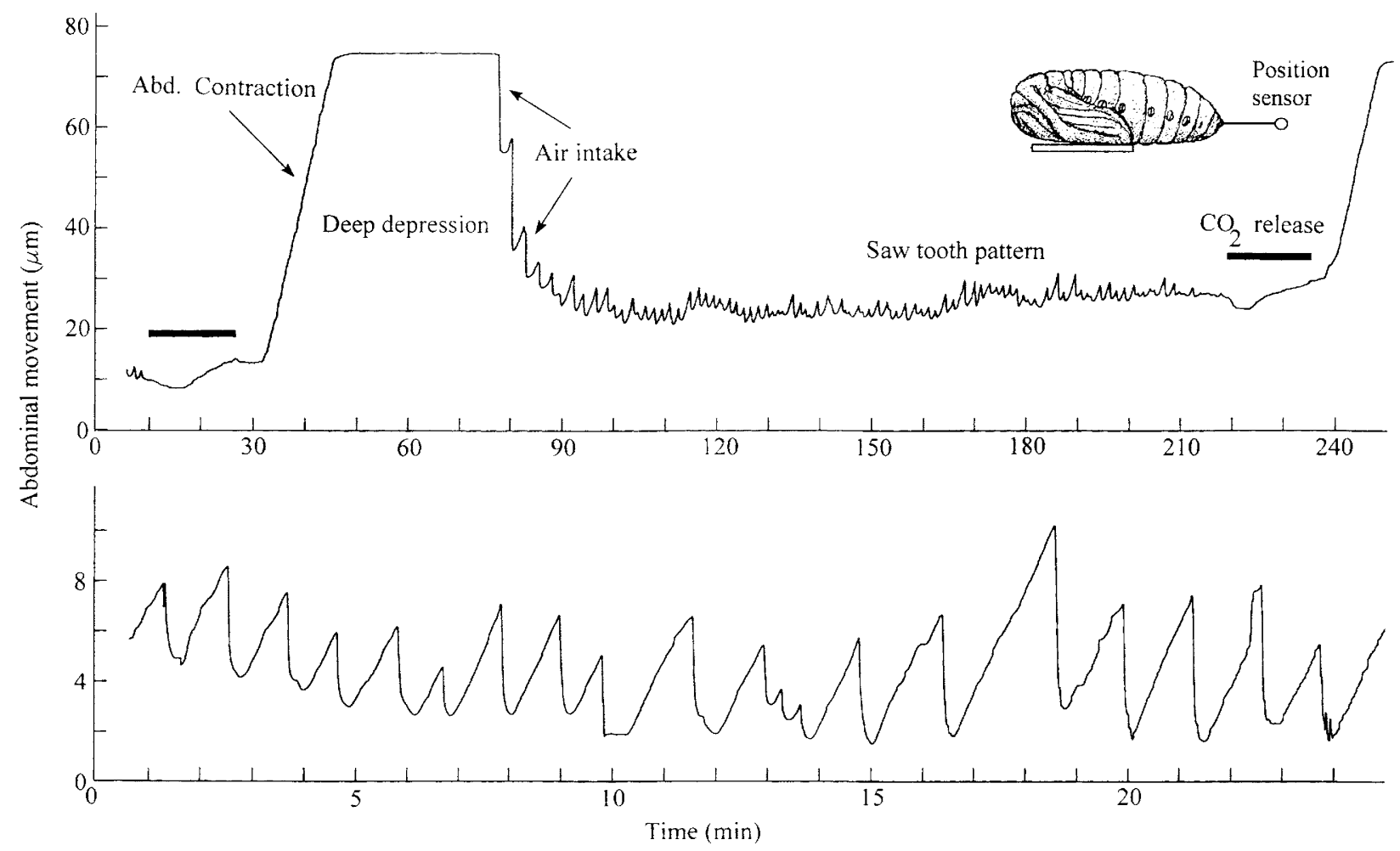

Fig. 7. Respiratory movements and relative changes in haemocoelic pressure recorded from the tip of the abdomen during the entire discontinuous respiration cycle (above) of a $3.4 \mathrm{~g}$ pupa at the end of diapause $\left(3-4 \mathrm{~h}\right.$ periodicity of the $\mathrm{CO}_{2}$ bursts; $22^{\circ} \mathrm{C}$. Lower record shows the detail of the saw tooth inspiration pattern. The rate of constant abdominal contraction (passive suction) is 4 $\mu \mathrm{m} / \mathrm{min}$

pause or mecanically disturbed pupae, were never recorded in unrestrained diapausing pupae.

\section{Closer look at deep depressions ("hills") and saw-tooth pattern of inspirations}

Inspired by the pioneering work of Schneiderman and his co-workers, we tried to measure "intratracheal" pressure through individual spiracles using hydraulic transducers and other sensors. Curiously enough, the pupae recognized the closed spiracle connected to the transducer within some 10 or $15 \mathrm{~min}$. From that point on the obstructed spiracular valve remained permanently open. The sensor started to transduce the regular patterns of changes in haemocoelic pressure. These results show that "intratracheal" pressure is actually identical with the haemocoelic or internal body pressure, due to the interconnection of all parts of the tracheal system. Under certain circumstances, the indirect recording of haemocoelic pressure through a spiracle appeared to be a good alternative method to the direct, invasive recordings from the haemocoele. For large scale measurements, however, the best method for monitoring discontinuous respiration was the use of position sensors attached to the tip of the abdomen.

A common example of a recording using position sensors is illustrated in Fig. 6. This recording is of the same pupa as used in Fig. 5, but after several months of diapause. Similar records obtained from another 25 diapausing pupae were used for a more detailed analysis of individual components of the discontinuous respiration cycle. The results can be briefly described as follows:

1. $\mathrm{CO}_{2}$ bursts occur at regular intervals in the middle of pupal diapause. They usually last 15 to $25 \mathrm{~min}$ (exceptionally up to $40 \mathrm{~min}$ ), with interburst periods mostly between 5 to $12 \mathrm{~h}$ (at room temperature). The records show the virtual absence of the saw-tooth pattern during the burst, suggesting constant ventilation of $\mathrm{CO}_{2}$ associated with the frequent opening and closing of different spiracular valves. The bursts of $\mathrm{CO}_{2}$ occurred for the first time during the immobile prepupal stage. After pupal ecdysis, the intervals between $\mathrm{CO}_{2}$ bursts became successively prolonged and the production of $\mathrm{CO}_{2}$ between the bursts fell to zero within 2 to 4 days. During post diapause development the process was reversed. The advanced pharate adults exhibited almost continuous $\mathrm{CO}_{2}$ release, which was associated with vigorous extracardiac pulsations and large ventilatory movements.

2. Deep depressions of haemocoelic pressure or "hills", associated with permanently closed spiracles, usually appeared after the extensive ventilation and termination of each $\mathrm{CO}_{2}$ burst (Fig. 7). Evaluation of a large number $(n=47)$ of prolonged posimetric records revealed that the "hills" were not obligatorily tied to termination of $\mathrm{CO}_{2}$ bursts. In 6 out of 27 post diapause pupae, for example, the "hills" appeared after the burst as well as in the middle of the interburst periods. There were also $\mathrm{CO}_{2}$ bursts without the consequent "hills" or, the "hills" came only after each second or third $\mathrm{CO}_{2}$ burst. These observations suggest that the periods when the spiracles are 


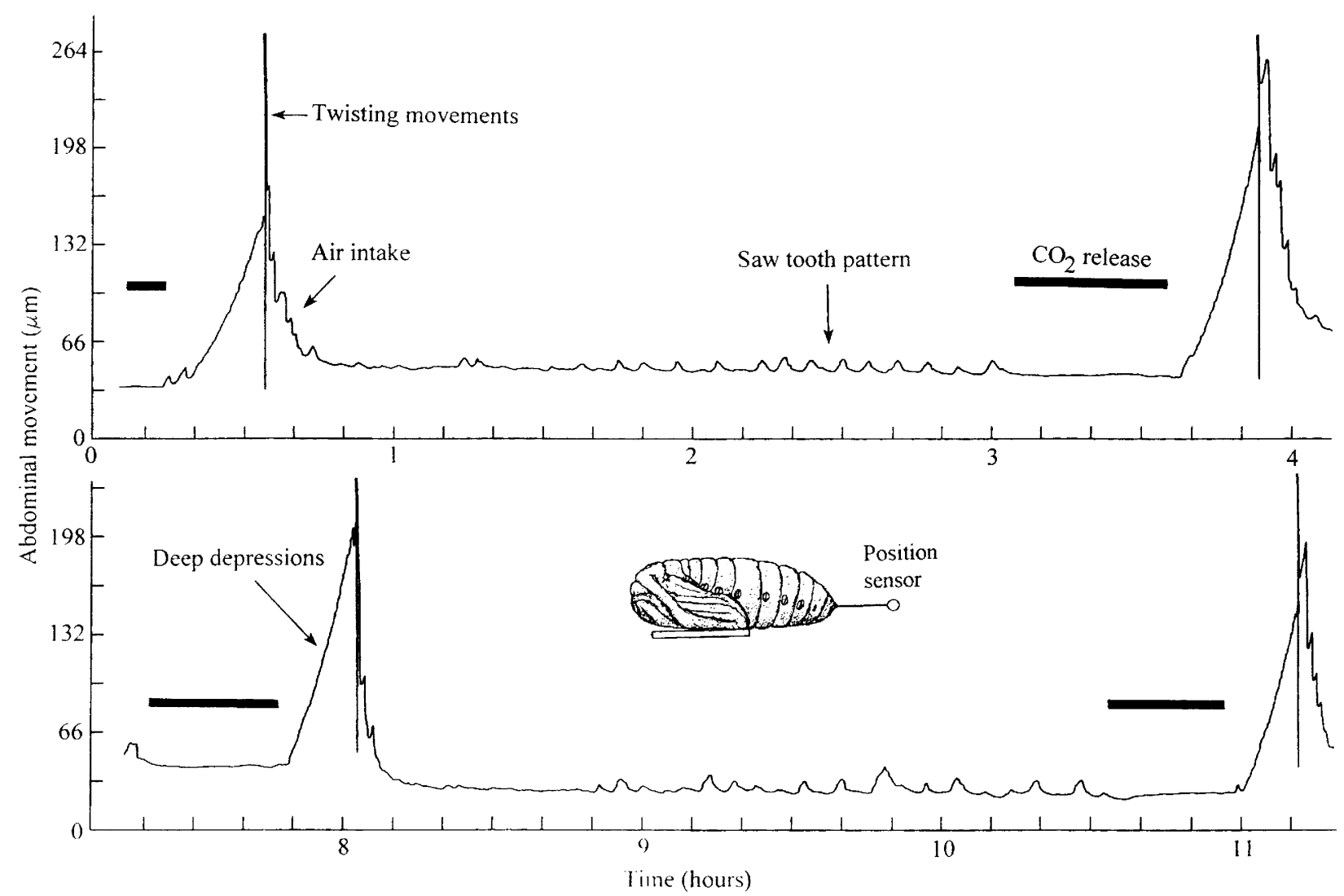

Fig. 8. Changes in haemocoelic pressure recorded indirectly from the tip of the abdomen of a diapausing $5.5 \mathrm{~g}$ pupa, at $25^{\circ} \mathrm{C}$ during 4 consecutive discontinuous cycles. Note the presence of large twisting movements during the deep depressions after each burst.

closed or deep depressions ("hills") did not represent an obligatory part of the discontinuous respiration cycles. This conclusion was also supported by the fact that the deep depressions (periods of permanently closed spiracles) disappeared with the appearance of extracardiac ventilatory pulsations during post diapause development. It is concluded, therefore, that the occasional periods of closed spiracles ("hills") are associated with functions other than respiration. Extensive variations in haemocoelic pressure during the "hills" may cause a temporary outflow and inflow of haemolymph from the wing lobes and other appendages and thus fulfill a circulatory function.

3. Large air intakes terminating the "hills" are mostly due to the flash-opening of the two prothoracic spiracular valves, which provide air exchange for the whole anterior half of the pupal body (exact microanemometric data will be presented elsewhere). The flash-openings caused relative pressure strokes of 50 to $100 \mathrm{~Pa}$ in haemocoelic pressure, which corresponded to a bulk inflow into the body of 40-60 $\mu 1$ of air. The instant surges in haemocoelic pressure may be also associated with circulatory functions. The long pupal appendages do not contain special accessory pulsatile organs and are not reached by pulsations of the dorsal vessel. There are tissue folds and septa that function as passive unidirectional pressure valves. The sudden increases in haemocoelic pressure or extracardiac pulsations can act on these valves to produce unidirectional circulation of haemolymph through the appendages.

4. The saw-tooth pattern in haemocoelic pressure and its mirror image in abdominal contraction are good physiological criteria for the determination of developmental and metabolic conditions. The intervals of inspirations are regulated by an homeostatic mechanism with the neuroendocrine centers located within thoracic ganglia in the ventral nerve cord. Fig. 6 shows the saw-tooth pattern in more detail. The range of these homeostatic regulations is quite small, from $2 \mu \mathrm{m}$ (= $4 \mathrm{~Pa}$ of pressure) to $7 \mu \mathrm{m}$ (= $14 \mathrm{~Pa}$ of pressure), with the average periodicity of the inspirations $1.17 \mathrm{~min}$. There are larger and smaller "teeth", suggesting the alternative use of different spiracles. The precise neuromotor control over the saw-tooth pattern can be demonstrated by the effects of mechanical irritation, stress, or strong acoustic signals. These treatments disturb the regular saw-tooth pattern, which is immediately replaced by several minutes of spiracular closure appearing on records as an atypical, abnormally large tooth. During post diapause development, due to enhanced metabolic activity, the passive inspirations are more frequent, eventually combining with large expiratory abdominal contractions (Fig. 6, lower record). After mechanical irritation or an increased ambient temperature, the "saw-tooth" pattern can temporarily disappear, which is mostly due to the continuous inflow of fresh air through permanently open thoracic spiracles. 


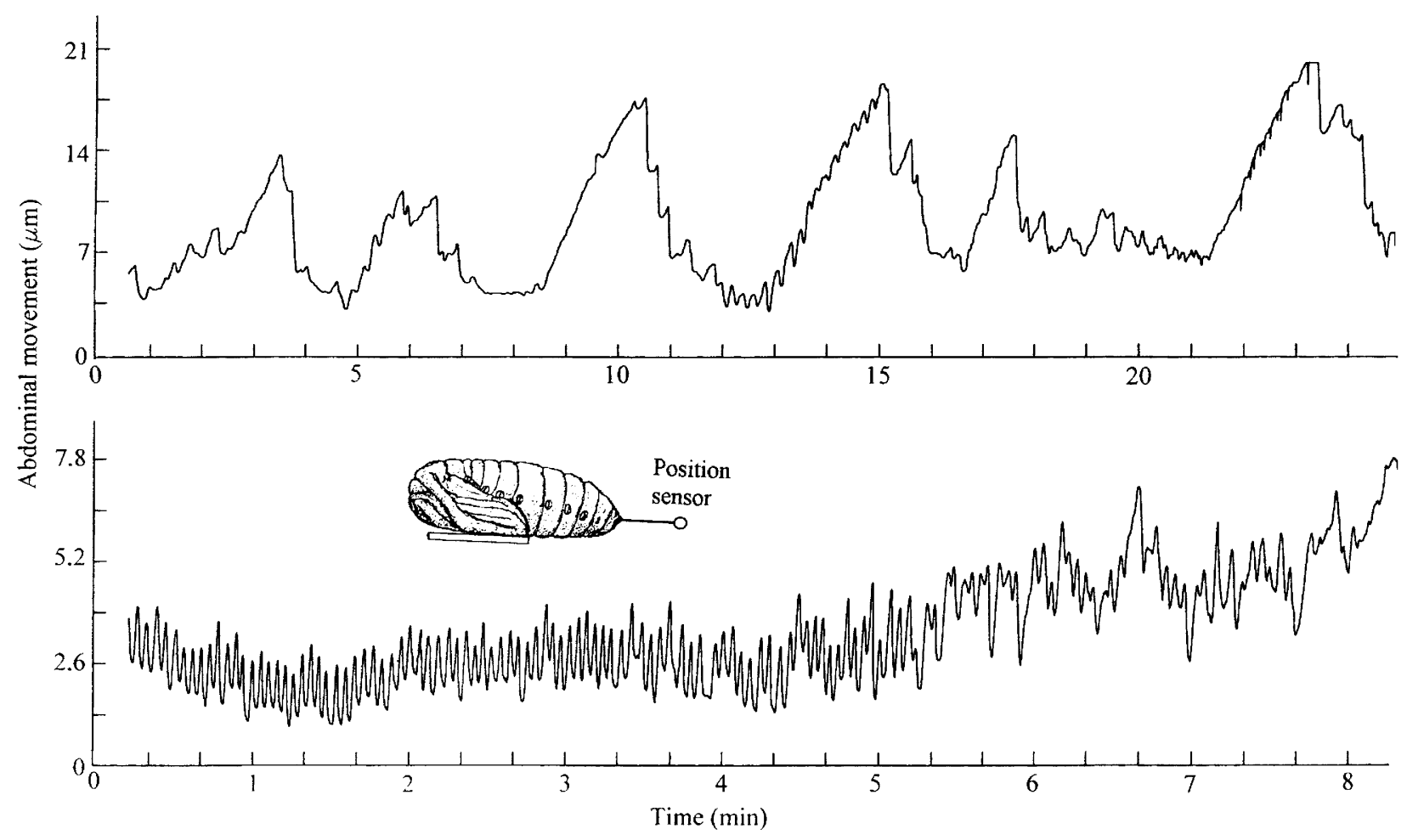

Fig. 9. Multiple medium size depressions in haemocoelic pressure recorded indirectly from the tip of the abdomen of a $5.4 \mathrm{~g}$ pupa at the beginning of pharate adult development. Lower record shows terminal part of an extracardiac pulsation ("fluttering") during a $\mathrm{CO}_{2}$ burst. The rate of abdominal contraction (passive suction) is $8 \mu \mathrm{m} / \mathrm{min}$, amplitude of the heartbeat $0.6 \mu \mathrm{m}$, amplitude of the extracardiac pulsation $2.5 \mu \mathrm{m}$ with a frequency of $18 / \mathrm{min}$.

5. The rate of abdominal contraction (pressure decline) is considered to be directly proportional to the $\mathrm{O}_{2}$ consumption of actively metabolizing tissues and cells. Volumetric relationships associated with vacuum formation within a pupa can be theoretically calculated from the cross-sectional area of the middle of the conical contractible segments (6th abdominal segment). For example, the diameter of the 6th abdominal segment of the pupa used in Fig. 7 was $14 \mathrm{~mm}$, which is equivalent to a cross sectional area of $153.8 \mathrm{~mm}^{2}$. The $4 \mu \mathrm{m} / \mathrm{min}$ rate determined for the abdominal contraction of this pupa would thus yield $0.61 \mu 1$ of $\mathrm{O}_{2}$ consumption per min $(36.9 \mu \mathrm{l}$ $\mathrm{O}_{2} / \mathrm{h}$, or $10.8 \mu \mathrm{O}_{2} / \mathrm{g} / \mathrm{h}$; at $22^{\circ}$ This shows that a relatively small fragment of these records can be successfully used for the assessment of metabolic rates during diapause and development of these pupae. Evaluation of the available records revealed the rates of abdominal contraction to be between 1.5 and $7 \mu \mathrm{m} / \mathrm{min}$ (mean value $4.5 \mu \mathrm{m} / \mathrm{min}$, SD $=1.3, n=35$, at $22^{\circ}$ for pupae in diapause, with the lowest values $(1.5 \mu \mathrm{m})$ recorded in the middle of the diapause period. Rates of abdominal contraction larger than $7 \mu \mathrm{m} / \mathrm{min}$ identified unequivocally pupae that had initiated post diapause development; rates of $20 \mu \mathrm{m} / \mathrm{min}$ and more indicated pharate adult development.

The constant rate of abdominal contraction (= vacuum formation, $\mathrm{O}_{2}$ consumption) did not follow a course as linear as in Fig. 5. The large pupae had a decreasing, partly curvilinear course of abdominal contraction, which can be observed in Fig. 6 (above). The lack of linearity is probably due to reduced elasticity of the intersegmental membranes. In contrast to diapause, the abdominal contractions of developing pupae show a mixture of different, actively regulated movements associated with extracardiac pulsations, large ventilatory movements and vigorous abdominal rotations. During this period of elevated respiratory metabolism, spiracular valves all close synchronously only sporadically and a vacuum does not develop. At this time, the deep depressions (periods when spiracles are closed) do not exist and the baseline haemocoelic pressure oscillates around values above the atmospheric level. An example of the described dynamic breathing pattern in the advanced pharate adult of Cecropia can be observed in Fig. 6 (lower record). There is a mixture of active expirations, cardiac pulsations (frequency $11 / \mathrm{min}$, amplitude $0.9 \mu \mathrm{m}$ ) and large ventilatory abdominal movements. A comparison of the upper and lower records in Figs 6 and 7 reveal large differences between the diapause and post diapause respiratory patterns.

Extensive observations on a large number of diapausing Cecropia pupae revealed that the functioning of the spiracular valves is under precise neuroendocrine control. This became evident in experiments in which relatively mild mechanical stimuli applied to pupal integument, or even acoustic stimuli resulted in the pupae immediately closing all the spiracular valves, which is easily recognized by the immediate decline in pressure (exceptional "hills"). This conclusion does not accord with the original assumptions about the passive opening and closing of the valves depending on the intratracheal gas composition. It 


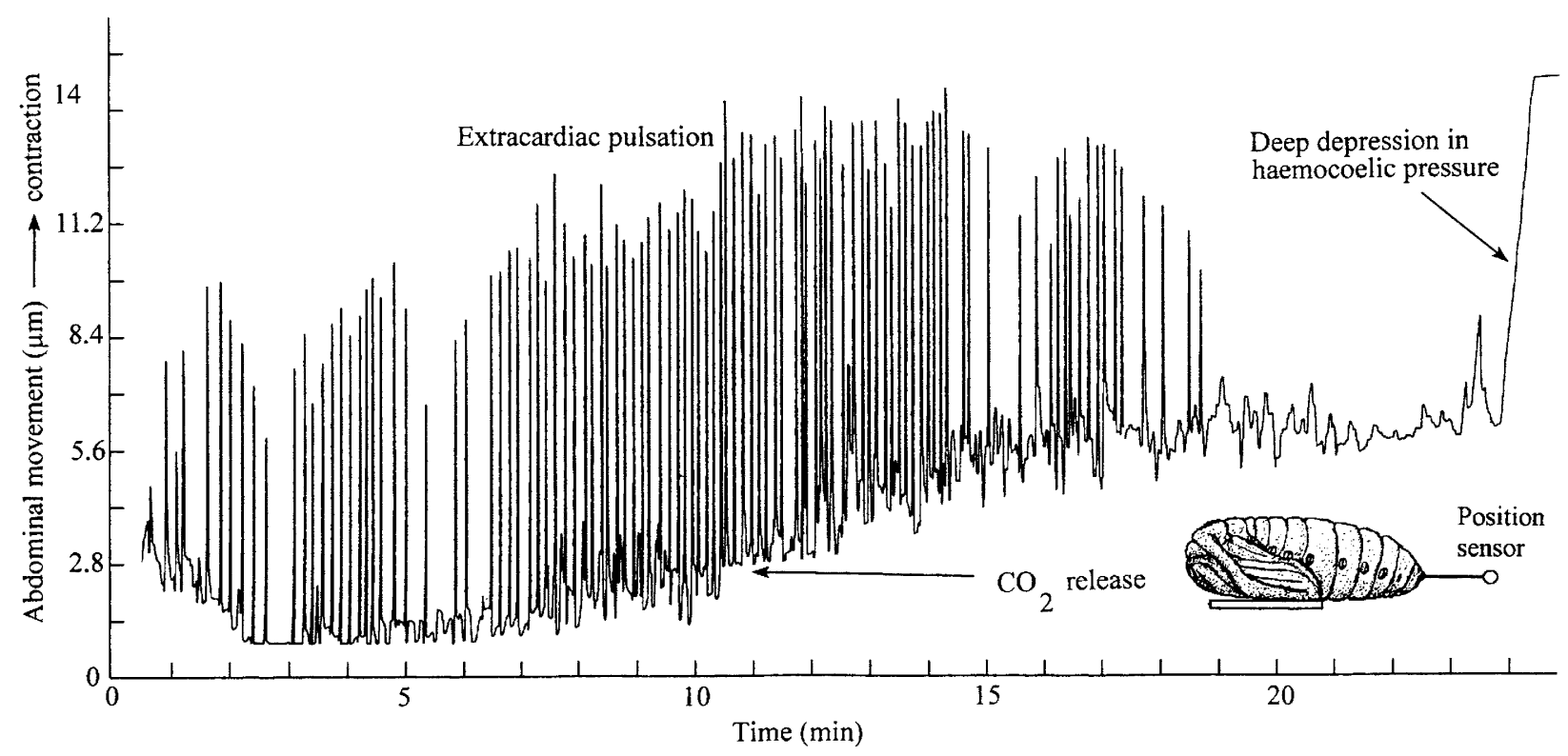

Fig. 10. High resolution record of an extracardiac pulsation ("fluttering") during a $\mathrm{CO}_{2}$ burst for a developing, $5.2 \mathrm{~g}$ pupa, 20 days before adult eclosion. The rate of abdominal contraction (passive suction) increased to $19 \mu \mathrm{m} / \mathrm{min}$.

is generally known that insect spiracular valves are forcibly opened when exposed to $\mathrm{CO}_{2}$ concentrations higher than $3 \%$. However, this is an emergency situation without a regulatory physiological value.

\section{Twisting movements and abdominal rotations}

Diapausing pupae of Cecropia remain immobile within the cocoon. It is obvious that the dorsal vessel alone cannot fully satisfy the circulatory demands of this relatively large insect. In addition to the deep depressions ("hills") there are other factors with potential circulatory importance. These are the periodically repeated peristaltic contractions of the intestine, which stir or mix haemolymph within the main body cavity. There are also large abdominal rotations and occasional twisting movements of the abdomen, which may potentially have both circulatory and respiratory functions. These movements are much larger than those that occur during passive inspiration or extracardiac pulsations.

Fig. 8 shows a common low power, long-lasting record of abdominal contractions in a diapausing pupa of Cecropia. There are 4 bursts of $\mathrm{CO}_{2}$ with the associated depressions ("hills") and a partly visible saw-tooth pattern of inspirations during the interburst period. There are also large, twisting movements of the abdomen at the end of each "hill". Surprisingly, these vigorous, repeated rotations of the abdomen have no ventilatory effect. This is documented by the fact that the movements take place when spiracular valves remain tightly closed and the previously established internal vacuum remains undisturbed. It is possible, therefore, that the sudden up and down changes in haemocoelic pressure associated with these movements have a circulatory function similar to the large intakes of air. Dissections revealed that the distal abdominal extremity is attached to fine ligaments leading to various visceral organs. The twisting movements or abdominal rotations certainly move the organs against each other, which may help to wash the organs with haemolymph. The twisting movements and rotations of the abdomen may thus prevent occlusion and necrotization of tissues among the densely packed pupal organs.

The regular occurrence of twisting movements and abdominal rotations shown in Fig. 8 can give a false impression about the presence of these movements as an essential part of the discontinuous respiration cycle. After evaluation of available records of this type $(n=39)$ we found that: (a) The movements occured during deep depressions, as recorded in Fig. 8 for 14 pupae; (b) They occurred exclusively in the middle of the interburst periods (4 pupae); (c) They occured quite irregularly, only once in several respiration cycles and with no clear association with the "hills" (9 pupae); (d) Occasionally, some diapausing pupae performed the twisting movements only once during a period of 6 to $24 \mathrm{~h}$ (at room temperature; 5 pupae) or not at all ( 7 pupae), which made monitoring of the twisting movements extremely difficult. In the course of post diapause development, the large abdominal movements occured quite frequently, sometimes with a periodicity of just a few minutes. In this case, the movements were positively associated with the ventilation of the tracheal system.

\section{Extracardiac pulsations and spiracular "fluttering"}

After pupal ecdysis, uninterrupted extracardiac haemocoelic pulsations occured with progressively increasing periods of rest before they faded out almost completely within the next 3 to 5 days. In the middle of the diapause period, when respiratory metabolism was at a minimum, extracardiac pulsations usually occured only in the relatively short intervals of $\mathrm{CO}_{2}$ bursts. The pulsations could be experimentally induced, however, by manipulation, mechanical irritation, an integumental injury or sudden increase in ambient temperature (removal from refrigeration). During the periods of passive suction inspirations 


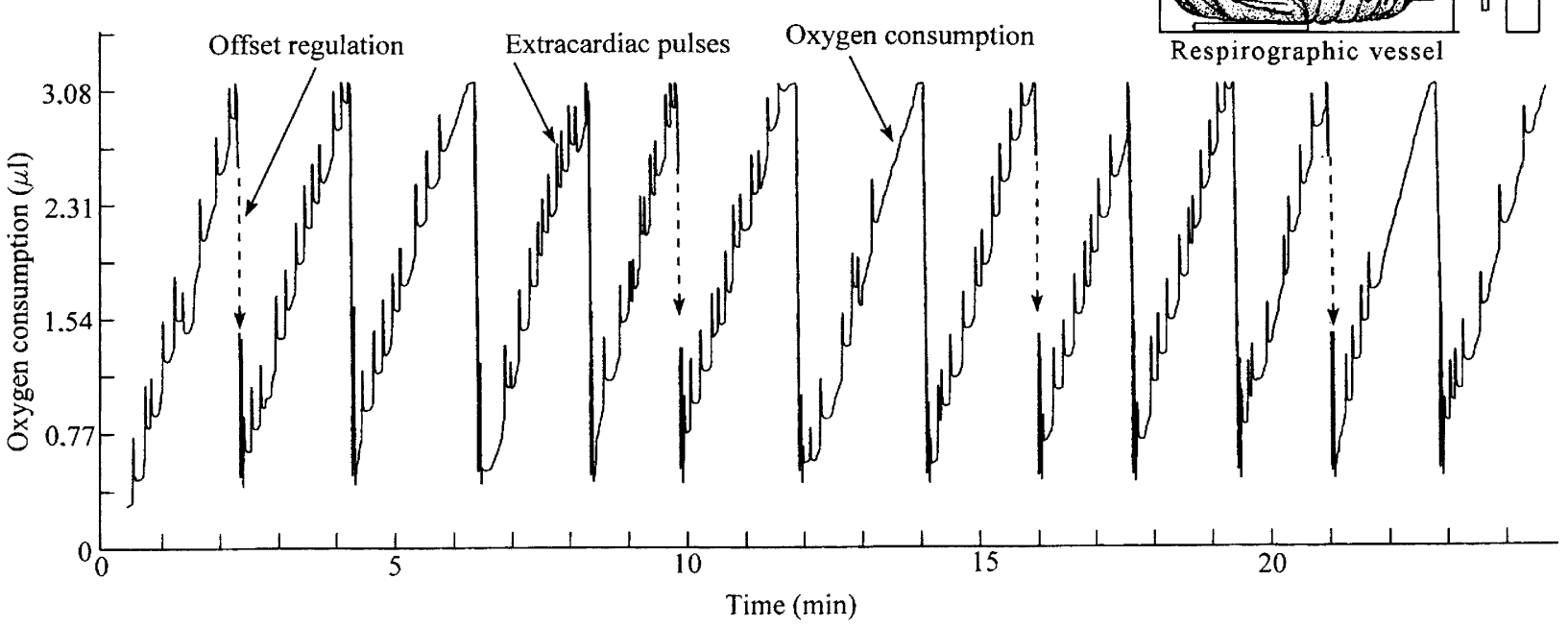

Fig. 11. Scanning respirographic record of $\mathrm{O}_{2}$ consumption during an interburst period of a $5.6 \mathrm{~g}$ pupa at the beginning of post dia-

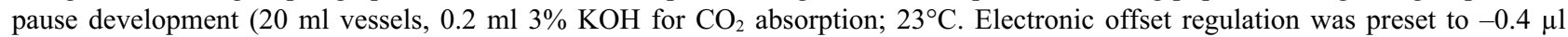
(zero) and $-3 \mu 1$ (maximum).

between $\mathrm{CO}_{2}$ bursts, extracardiac pulsations were never recorded.

Examples of cardiac and extracardiac pulsations can be found in Fig. 9. The upper record shows the modified saw-tooth pattern with a relatively constant rate of abdominal contraction $(8 \mu \mathrm{m} / \mathrm{min})$ and several inspirations per minute. Abdominal contractions were modulated by retrograde cardiac pulsations (frequency 5-6 pulses /min) of rather small amplitude (350-600 nanometers). The lower record shows the terminal part of an extracardiac pulsation (frequency 18 pulses/min; amplitude 2.5 $\mu \mathrm{m})$ that was taken at the end of one $\mathrm{CO}_{2}$ burst. When related to pupal length $(45 \mathrm{~mm})$, the amplitude of the heartbeat was only $1 / 100000$ th and that of an extracardiac pulsation, $1 / 18000$ th of the body length. It is obvious that without the help of electronic devices these pulsations could not be recorded and visualized.

Extracardiac pulsations ("fluttering") are progressively restored and increase in the course of post diapause development. It is essential to know that, in contrast to the myogenic principle of the heartbeat, extracardiac pulsations in haemocoelic pressure are neurogenic. They are stimulated by cholinergic neuroendocrines secreted by centers located in the thoracic ganglia of the ventral nerve cord (see discussion). After the termination of diapause and associated with the increasing metabolic rate, extracardiac pulsations continuously increase in amplitude and pumping efficiency. In order to document this a record of a large extracardiac haemocoelic pulsation that occured during a selected $\mathrm{CO}_{2}$ burst in an advanced post diapause pupa of Cecropia, 20-days before adult eclosion, is presented (see Fig. 10). The relatively high rate of abdominal contraction (visible at the end of Fig. 10) indicates values as high as $18 \mu \mathrm{m} / \mathrm{min}$. The frequency of individual extracardiac contractions was lower, only some 7 to 9 contractions per minute, however, the amplitude of individual contractions was a large, more than $10 \mu \mathrm{m}$.
Using micro-anemometric techniques for recording the passage of air through individual spiracles, revealed that the coordinated opening and closing of spiracular valves occured in synchrony with individual strokes of the extracardiac pulsation (to be published elsewhere). These and other findings provide evidence for the coordinated pulsation of spiracular valves during extracardiac pulsations. Obviously, similar observations prompted H.A. Schneiderman, half of a century ago, to describe the phenomenon of spiracular "fluttering".

\section{Respirographic monitoring of $\mathrm{O}_{2}$ consumption and $\mathrm{CO}_{2}$ output}

The constant volume scanning microrespirographic method records changes in gas composition within a closed respiratory vessel. This method depends on electronic offset regulation, which performs automatic zeroing and offset regulations within the predetermined offset limits. The records take the form of separate scanning episodes, in which the cummulative curve of $\mathrm{O}_{2}$ consumption or $\mathrm{CO}_{2}$ output oscillate between the preset zero and maximum output limits.

Fig. 11 shows an example of a scanning respirographic record of $\mathrm{O}_{2}$ consumption, which was obtained from a post diapause pupa during the period of a $\mathrm{CO}_{2}$ burst with extracardiac pulsation. The released $\mathrm{CO}_{2}$ was absorbed in solution of $\mathrm{KOH}$ present within the respiratory compartment. There are 12 scanning episodes in which the cummulative curve for the consumption of $\mathrm{O}_{2}$ moves from zero (set at $0.4 \mu \mathrm{l}$ ) to an electronic offset limit (set at -3 $\mu \mathrm{l}$ of $\mathrm{O}_{2}$ ). The record shows a more or less constant course of $\mathrm{O}_{2}$ consumption $\left(1.9 \mu \mathrm{l} \mathrm{O}_{2} / \mathrm{min},=20.3 \mu \mathrm{l}\right.$ $\mathrm{O}_{2} / \mathrm{g} / \mathrm{h}$ ). This rate is quite common for early post diapause pupae. The respirographic records of $\mathrm{O}_{2}$ consumption have generally a smooth course. In special cases, such as in Fig. 11, the course of $\mathrm{O}_{2}$ consumption is modified by relatively small, $0.3 \mu \mathrm{l}$ negative pressure peaks, with a 


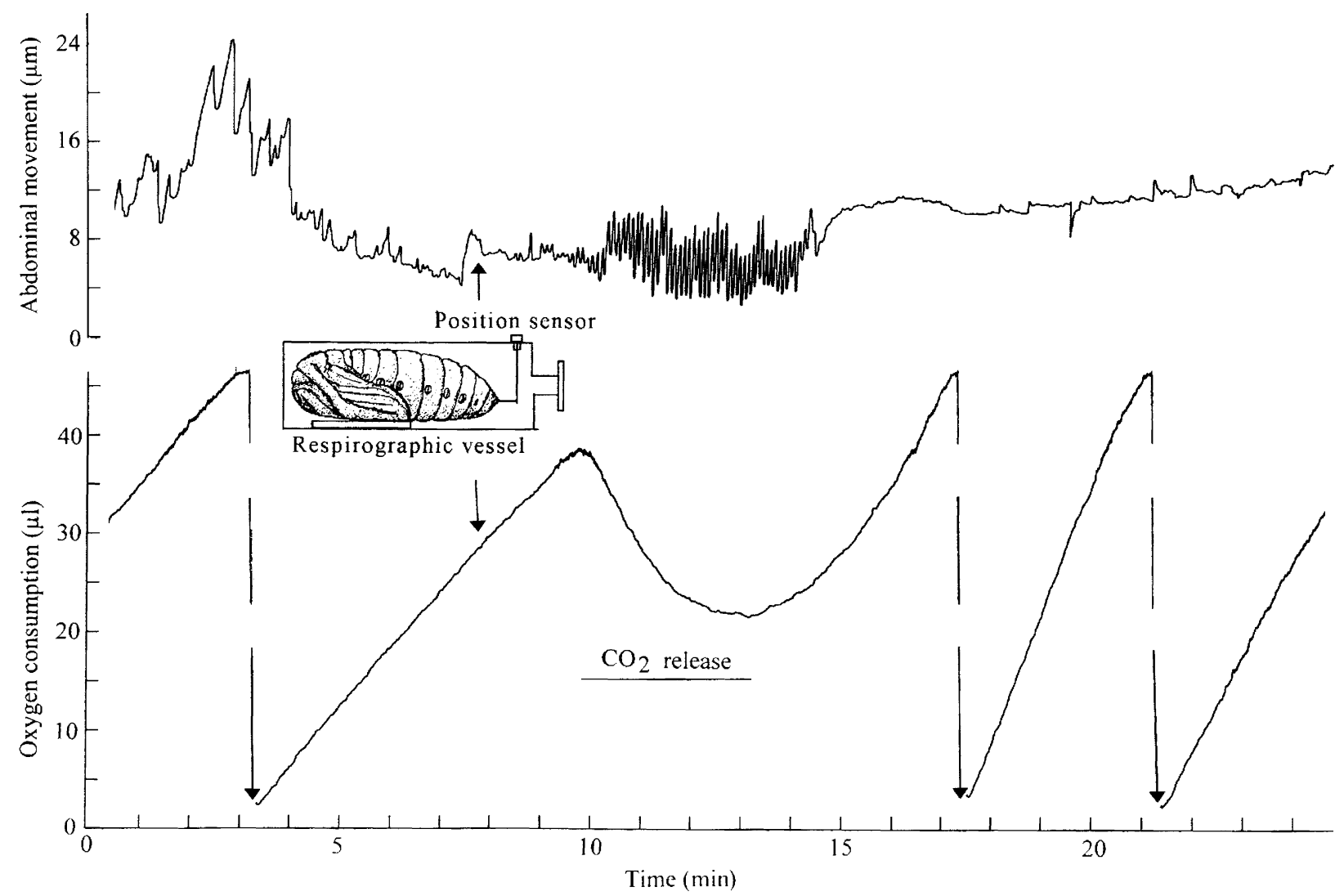

Fig. 12. Simultaneous respirographic record of abdominal contractions (above) and $\mathrm{O}_{2}$ consumption during early post diapause development for a $5.2 \mathrm{~g}$ pupa, at $25^{\circ} \mathrm{C}$. The extracardiac pulsation (frequency $11 / \mathrm{min}$, amplitude $4 \mu \mathrm{m}$ ) occurs during the relatively short burst of $\mathrm{CO}_{2}$ (lower record), which is attenuated by the presence of $\mathrm{CO}_{2}$ absorbent. The usual deep depression after the burst does not occur. Respirographic offset regulation was set between zero and $-45 \mu \mathrm{l} ; 25 \mathrm{ml}$ vessels contained $0.2 \mathrm{ml}$ of $3 \% \mathrm{KOH}$ for $\mathrm{CO}_{2}$ absorption.

periodicity of 5 to 9 strokes per minute. These modifications were evidently caused by individual contractions of an extracardiac haemocoelic pulsation.

Intimate relationships between the gaseous exchange and haemocoelic pressure are apparent in the simultaneous respirographic recording of $\mathrm{O}_{2}$ consumption and abdominal contractions ( $n=14$ pupae measured). Fig. 12 shows a portion of one such recording of a post diapause pupa with an elevated metabolic rate and a short $\mathrm{CO}_{2}$ burst but no closed spiracle phase. The upper record in Fig. 12 shows an increased rate of abdominal contraction, which is common for post diapause pupae $(20 \mu \mathrm{m} / \mathrm{min}$, see 2-5 min of recording time). There are extracardiac ventilatory pulsations (contractions $11 / \mathrm{min}$, amplitude 6 $\mu \mathrm{m})$ during the relatively short burst of $\mathrm{CO}_{2}$. The lower curve in Fig. 12 shows simultaneous changes in $\mathrm{O}_{2}$ consumption. The rate of $\mathrm{O}_{2}$ consumption was relatively low before the $\mathrm{CO}_{2}$ burst $(5 \mathrm{nl} / \mathrm{min},=54.5 \mu \mathrm{l} \mathrm{O} / \mathrm{g} / \mathrm{h})$, attaining its maximum $(11.5 \mathrm{nl} / \mathrm{min},=125 \mu \mathrm{l} \mathrm{O} / \mathrm{g} / \mathrm{h})$ immediately after the burst. This shows that, in contrast to the widespread belief in a constant $\mathrm{O}_{2}$ consumption during discontinuous respiration, the actual rate of $\mathrm{O}_{2}$ consumption is substantially higher after each $\mathrm{CO}_{2}$ burst. It has to be pointed out that the amount of $\mathrm{CO}_{2}$ produced by a pupa is greater than indicated in Fig. 12, because a substantial part of the $\mathrm{CO}_{2}$ is absorbed by the $\mathrm{KOH}$ solution. These results provide good evidence that the release of $\mathrm{CO}_{2}$ during the burst is actively regulated by ventilatory movements and not by simple passive diffusion.

Novel and physiologically very important relationships in the gaseous exchanges that occur in pupae were obtained by respirographic recordings in the absence of $\mathrm{CO}_{2}$ absorbent. In this case, the devices recorded a different ratio between $\mathrm{O}_{2}$ consumption and $\mathrm{CO}_{2}$ output $\left(\mathrm{CO}_{2}-\mathrm{O}_{2}\right.$ ratio). An instructive example is the one $\mathrm{CO}_{2}$ burst reproduced from several different records of diapausing pupae $(n=8)$ presented in Fig. 13. In this case, the scanning mechanism uses two offset limits. There is an upper limit for negative pressure changes $\left(=\mathrm{O}_{2}\right.$ consumption) and a lower offset limit for positive pressures $\left(\mathrm{CO}_{2}\right.$ release minus $\mathrm{O}_{2}$ consumption). Experiments using repeated respirographic recordings with and without the $\mathrm{CO}_{2}$ absorbent revealed unequivocally that diapausing pupae of Cecropia vented gaseous $\mathrm{CO}_{2}$ exclusively during the burst periods. In other words, there was no accumulation of gaseous $\mathrm{CO}_{2}$ within the tracheal system during the interburst period, which does not accord with the old theories. The values of the $\mathrm{CO}_{2}-\mathrm{O}_{2}$ ratio were identical with those recorded during the interburst periods with $\mathrm{O}_{2}$ consumption. During diapause, gaseous $\mathrm{CO}_{2}$ was liberated exclusively during the bursts. At the beginning of adult development, however, $\mathrm{CO}_{2}$ was released partly during each burst and also between bursts. Later on, how- 


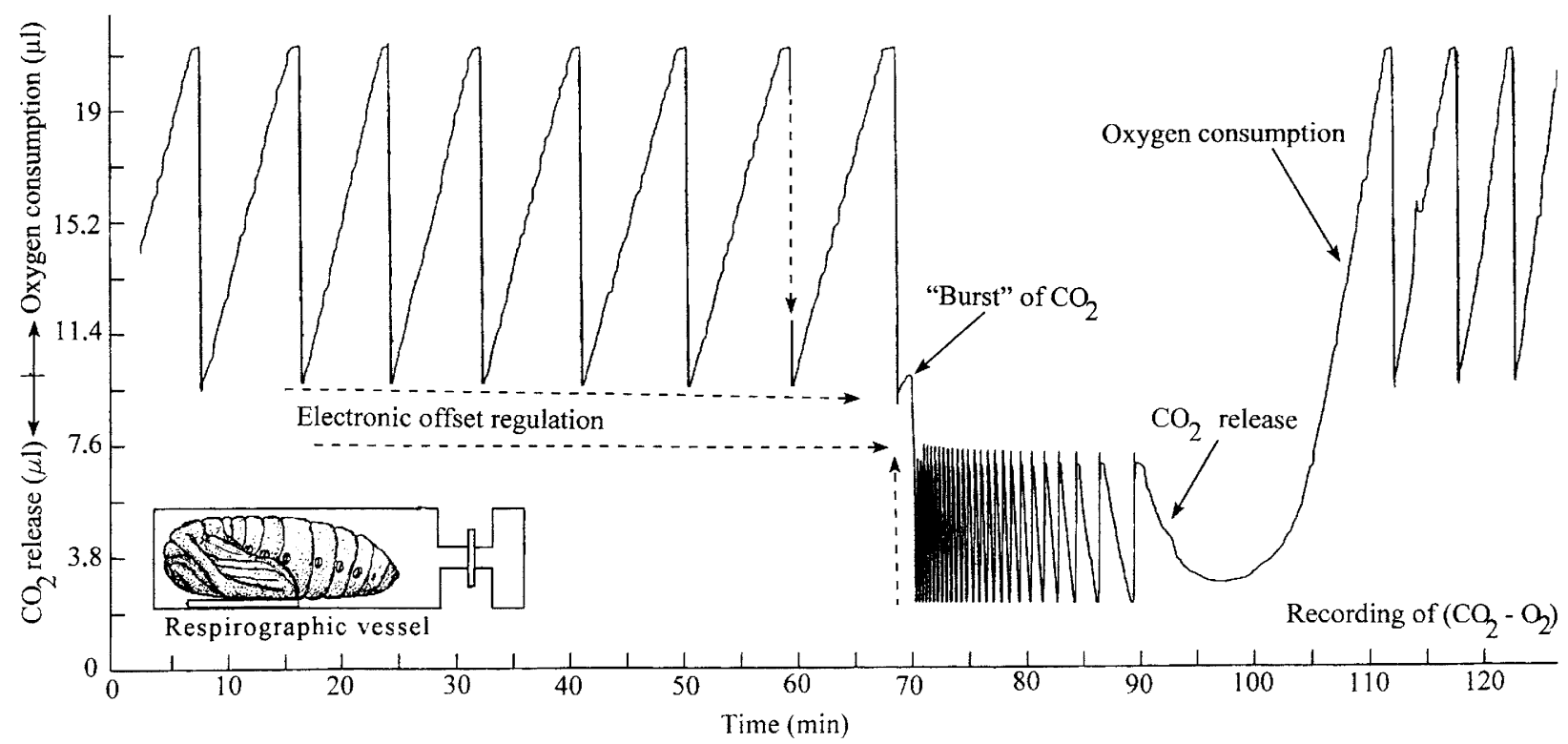

Fig. 13. Respirographic record of $\left(\mathrm{CO}_{2}-\mathrm{O}_{2}\right)$ ratio before, during and after one $\mathrm{CO}_{2}$ burst taken from a prolonged overnight recording ( $3-5 \mathrm{~h}$ periodicity of the bursts) of a $5.6 \mathrm{~g}$ post diapause pupa, 25 days before adult eclosion; at $23^{\circ} \mathrm{C}$. The scanning system, with a respiratory vessel of $25 \mathrm{ml}$ capacity, was set for two offset limitations; one for negative pressures $(21 \mu \mathrm{l})$ and the other for positive pressures (at $1.9 \mu \mathrm{l}$ of relative pressure scale) for $\mathrm{CO}_{2}$ release. Upon reaching one or the opposite offset limits, internal valves briefly opened and the internal pressure equilibrated with atmospheric pressure (set close to $8 \mu \mathrm{l}$ ); respiratory vessel of $40 \mathrm{ml}$ capacity.

ever, during advanced adult development, $\mathrm{CO}_{2}$ was released more or less continuously.

The record in Fig. 13 shows only one out of 6 consecutive $\mathrm{CO}_{2}$ bursts recorded in a prolonged recording. The course of the respirographic curves for all the remaining bursts was surprisingly similar. It is likely that the pattern shown in Fig. 13 is the characteristic and general pattern of the discontinuous respiration cycle. It has several new, physiologically important implications: (1) The rate of $\mathrm{O}_{2}$ consumption is not constant during the interburst period. It is relatively high after each $\mathrm{CO}_{2}$ burst $(3 \mu \mathrm{l} \mathrm{O} / \mathrm{min},=$ $33 \mu \mathrm{l} / \mathrm{g} / \mathrm{h}$ in Fig. 13) and then gradually decreases before the next burst $(1.2 \mu \mathrm{l} / \mathrm{min},=12.8 \mu \mathrm{l} \mathrm{O} / \mathrm{g} / \mathrm{h})$; (2) Gaseous $\mathrm{CO}_{2}$ bursts suddenly from zero, with the initial rates occasionally exceeding the rate of $\mathrm{O}_{2}$ consumption by 20 -fold or more; (3) The velocity of gaseous $\mathrm{CO}_{2}$ production is fastest at the beginning and then declines gradually until it ceases; (4) The amount of $\mathrm{CO}_{2}$ (uncorrected for reciprocal $\mathrm{O}_{2}$ consumption) released during a $25 \mathrm{~min}$ burst is $150 \mu \mathrm{l}$ (Fig. 13). The corrected amount of $\mathrm{CO}_{2}$ calculated for a $25 \mathrm{~min}$ burst $(210 \mu \mathrm{l})$ agrees stoichiometrically with the expected 0.7 value of the respiratory quotient $\left(\mathrm{CO}_{2} /\right.$ $\mathrm{O}_{2}$ ); 5. The most important respirometric implication of the data in Fig. 13 is that the instant liberation of gaseous $\mathrm{CO}_{2}$ is controlled by an induced liquid-to-gas volatilization of $\mathrm{CO}_{2} ; 6$. It is concluded, therefore, that the production of $\mathrm{CO}_{2}$ during the burst proceeds on the basis of an homeostatically regulated chemical process, such as enzymatic hydration of metabolically formed carbonic acid; 7 . Finally, these experiments show that the bulk of $\mathrm{CO}_{2}$ produced during the burst was not previously stored within the tracheal system (which was postulated by the old concept), because there appears to be no diffusive transport of gas between different parts of the closed volumetric system.

The last difference between the old and recent view of discontinuous respiration in insects is in the regulatory mechanisms. The old, mechanistic concept assumes passive regulation determined by changes in the composition of respiratory gases. There is convincing evidence, however, that the discontinuous respiration cycles are actively regulated by the neuroendocrine system. This evidence is based mainly on the fact that a non scheduled burst of $\mathrm{CO}_{2}$ can be induced by mechanical irritation, temperature or pressure stress or electrical shocks. In addition, spontaneous anomalies in the otherwise constant appearance of $\mathrm{CO}_{2}$ bursts are often observed on respirographic records, such as duplicate or triplicate bursts occuring in the middle of regular interburst periods or a combination of large and small $\mathrm{CO}_{2}$ bursts. The differential respirographic record in Fig. 14 indicates that a homeostatic mechanism regulating the production of gaseous $\mathrm{CO}_{2}$ from bicarbonate buffers can be physiologically turned on and off. In addition, this record confirms previous statements that the actual rates of $\mathrm{O}_{2}$ consumption are always lower before (here $1.2 \mu \mathrm{l} / \mathrm{min},=13.3 \mu \mathrm{l} \mathrm{O} / \mathrm{g} / \mathrm{h}$ ) than after each $\mathrm{CO}_{2}$ burst (here $2.1 \mu \mathrm{l} / \mathrm{min}$, = $23 \mu \mathrm{l} \mathrm{O} / \mathrm{g} / \mathrm{h}$ ). During respirographic recordings of this type $(n=17)$, the average duration of each $\mathrm{CO}_{2}$ burst is from 20 to $25 \mathrm{~min}$ in the middle of the diapause period at room temperature, with the average duration of the interburst periods from 5 $\mathrm{h}$ to $16 \mathrm{~h}$. The amounts of $\mathrm{CO}_{2}$ released at each burst ranged from 150 to $380 \mu 1$. 


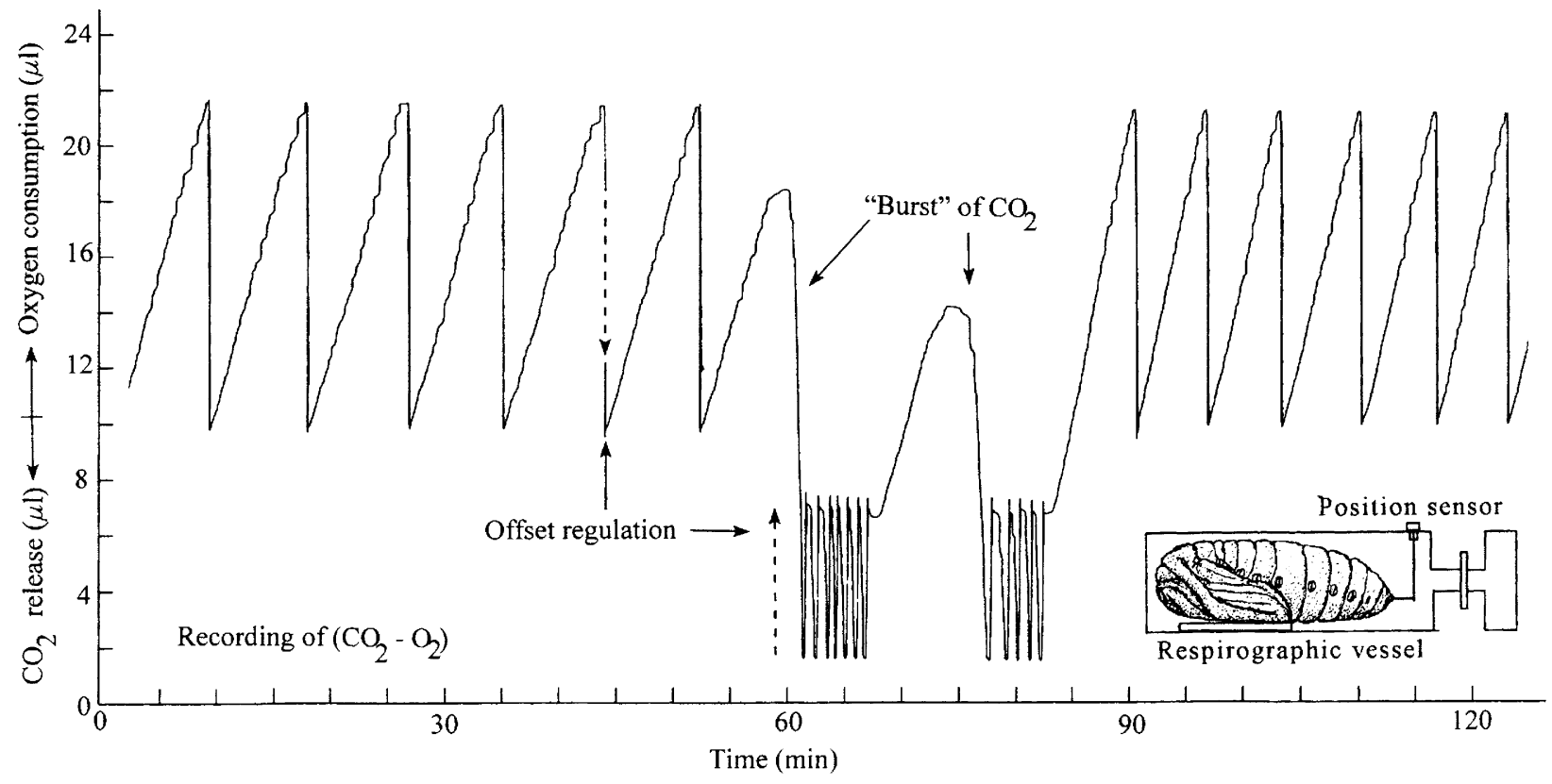

Fig. 14. Scanning respirographic record of $\left(\mathrm{CO}_{2}-\mathrm{O}_{2}\right)$ ratio as in Fig. 12 of a diapausing, $5.4 \mathrm{~g}$ pupa (8-10 h burst periodicity; $23^{\circ} \mathrm{C}$ which shows different rates of $\mathrm{O}_{2}$ consumption before and after $\mathrm{CO}_{2}$ bursts, separated by $10 \mathrm{~min}$ of rest.

\section{DISCUSSION}

Between 1953 and 1974, Schneiderman and his colleagues published a number of elegant studies on the discontinuous respiration cycles of Cecropia silkworms (see for example, Schneiderman \& Williams, 1955; Levy \& Schneiderman, 1958, 1966a, b, c; Schneiderman, 1956, 1960; Schneiderman \& Schechter, 1966; Brockway \& Schneiderman, 1967; Burkett \& Schneiderman, 1974a, b). Indoctrinated by the diffusion theory of Krogh (1920), they believed at that time that the pupae of Cecropia could easily satisfy their respiratory demands by passive diffusion of $\mathrm{O}_{2}$ and $\mathrm{CO}_{2}$ through the spiracles, without the necessity of ventilatory movements. Unfortunately, this model of insect respiration still persists (Kestler, 1985; Lighton, 1996; Wasserthal, 1996; Hetz \& Bradley, 2005; Qinlan \& Gibbs, 2006; Chown et al., 2006; Klowden, 2007; Contreras \& Bradley, 2009).

The original concept of discontinuous respiration in Cecropia, interpreted and misinterpreted many times in numerous review articles (Buck, 1962; Miller, 1981; Kestler, 1985; Lighton, 1996; Wasserthal, 1996; Chown et al., 2006), assumed continuous diffusion and accumulation of $\mathrm{CO}_{2}$ within the tracheal system. The intratracheal concentrations of $\mathrm{CO}_{2}$ were accordingly thought to increase up to as much as $6 \%$, which was previously known to cause the opening of the spiracular valves. The accumulated $\mathrm{CO}_{2}$ was assumed to diffuse out of the body through widely open spiracles, producing thus a discontinuous burst of $\mathrm{CO}_{2}$ (Schneiderman, 1960). The theory was not well founded because an extensive review of the respiratory physiology of insects, published before that time (see Kuznetzoff, 1953) listed numerous examples of the apparent toxicity of $\mathrm{CO}_{2}$ to insects at concentrations above $2 \%$, which is associated with narcotization and severe paralysis of neuromuscular functions. Our results show that there is no accumulation of gaseous $\mathrm{CO}_{2}$ during the interburst periods in Cecropia. This corroborates earlier findings (Sláma, 1988, 1999) that the spiracular valves alternatively open, close or pulsate during a $\mathrm{CO}_{2}$ burst, but do not all remain widely open.

The above results show that during their pioneering work Schneiderman and his co-workers made a few minor misinterpretations. These errors were later accentuated and incorporated into an innacurate theory of DGC. The misinterpretations can be briefly summarised as follows: (1) Incorrect conclusion that $\mathrm{CO}_{2}$ accumulates in the trachea up to a concentration of $6 \%$ during interburst periods; (2) Incorrect theories associated with the passive, purely diffusive transfer of $\mathrm{CO}_{2}$ through spiracles; (3) Overlooked existence of ventilatory movements regulated by the neuroendocrine system; (4) Incorrect roles ascribed to permanently closed spiracles during the deep depressions ("hills"), and; (5) Mysterious "fluttering" of spiracular valves occuring before the $\mathrm{CO}_{2}$ bursts. These interpretations, which stem from the diffusion theory of Krogh (1920), are still widely accepted and cited in the literature (reviews by Kuznetzoff, 1953; Wigglesworth, 1965; Kestler, 1985; Ligton, 1996), including current textbooks on insect physiology (Nation, 2002; Klowden, 2007).

It is difficult to argue against these half-century old and widely disseminated respiratory doctrines (see Lighton, 1996; Chown et al., 2006; Contreras \& Bradley, 2009). However, they do not coincide with recent research findings. The neuroendocrine system of insects is extremely sensitive to hypercapnia induced by the increased accumulation of gaseous $\mathrm{CO}_{2}$ (Kuznetzoff, 1953). High concentrations of $\mathrm{CO}_{2}$ are toxic. It induces deep neuromuscular paralysis and asociated opening of spiracular valves, which leads to desiccation. In this respect, Schneiderman's (1960) suggestion that the accumulation 
of $\mathrm{CO}_{2}$ may result in cocentrations as high as $6.7 \%$ during interburst periods is unrealistic. The danger of hypercapnia could account for the retention of $\mathrm{CO}_{2}$ in the form of liquid carbonate buffers until the very last moment prior to the $\mathrm{CO}_{2}$ burst. It is also the main reason for evolution of the chemical liberation of gaseous $\mathrm{CO}_{2}$ (see Point No. 1, above).

The output of $\mathrm{CO}_{2}$ during each burst could be enhanced to some degree by its diffusion through open spiracular valves. The results clearly show, however, that diffusion alone is not sufficient. Rapid removal of $\mathrm{CO}_{2}$ during a burst needs to be further enhanced by the convective bulk outflow of the gas through the spiracles (Point No. 2). The flow of gas is controlled by precise neuroendocrine regulation and unidirectional ventilation of $\mathrm{CO}_{2}$ through only some, selectively opened spiracles (Point No. 3). The resulting extracardiac haemocoelic pulsations, which are responsible for spiracular "fluttering" (Point No. 4), are a physiologically unique example of neuromotoric coupling between the pulsation of individual spiracular valves and the pumping contractions of intersegmental abdominal muscles (abdominal pressure pump). The selective advantage of these physiological adaptations depends on a homeostatically controlled, unidirectional flow of air through the determined spiracles (review by Sláma, 2009; Sláma et al., 2007). There are many ideas about how insects breath without loosing much water, which need to be discussed. Let us explain at least some of these points, using the principal criteria of the axiomatic DGC; a theory about open, closed and fluttering spiracles.

\section{Open spiracles and the $\mathrm{CO}_{2}$ bursts}

Insect integument is coated with hydrophobic, nonpolar waxes or hydrocarbons, which minimize the escape of water by diffusion through the surface of the body (Wigglesworth, 1965). In addition, terrestrial insects have evolved sophisticated mechanisms for preventing the loss of water via the spiracles (Kestler, 1985; Lighton, 1996; Sláma, 2009). Water conservation is very important in insects as they have a more than 100-fold greater gaseous exange than verterates and humans (Sláma, 2010). Therefore, the successful survival of terrestrial insects depends on the efficient neutralization of respiratory acidaemia produced by the metabolic formation of carbonic acid. According to Sláma et al. (2007), there are several ways of neutralizing respiratory acidaemia: (a) Passive diffusion of $\mathrm{CO}_{2}$ produced in the tissues into the tracheal system and out through widely open spiracles; (b) Convective ventilation of intratracheal $\mathrm{CO}_{2}$ through selected spiracles; (c) Chemical production of $\mathrm{CO}_{2}$ and its bulk outflow through selected spiracles, and; (d) Chemical production of $\mathrm{CO}_{2}$ enhanced by actively regulated ventilation. The first alternative (a), which is consistent with Krogh's (1920) conclusions but would not prevent the rapid escape of water vapour by diffusion from the body. The second alternative (b) was neglected for a long time because of the supposed absence of respiratory movements (in Cecropia, these movements were rediscovered too late by Brockway \& Schneiderman in 1967). The alternatives (c) and (d), i.e. chemical production of $\mathrm{CO}_{2}$ bursts was dicussed and rejected a long time ago by Buck $(1956,1962)$. The results presented here provide good experimental evidence that the chemical production of $\mathrm{CO}_{2}$ bursts (alternatives $\mathrm{c}$ and $\mathrm{d}$ ) is the dominant respiratory adaptation of diapausing pupae of Cecropia and, according to Sláma (2009), is a general respiratory adaptation occuring in a number of other insect species and taxonomic groups.

Krogh's theory (1920) was seriously criticised many times (cf. Kuznetzoff, 1953), but the critiques were never decisive because of a lack of experimental data. Kestler (1985) re-examined the theory and proposed the diffusive/convective model, which corresponded better with his model of water retention in Periplaneta. Schneiderman \& Williams (1955) used the conventional Warburg manometric technique for their respirometric measurements. The results presented here (see Figs 11 to 14) are quite consistent with their data, except for a minor correction with respect to a constant rate of $\mathrm{O}_{2}$ consumption between the bursts. These recordings show higher rates of $\mathrm{O}_{2}$ consumption after each burst, which may be explained by the subsequent decline in the partial pressure of $\mathrm{O}_{2}$ and increase in the partial pressure of $\mathrm{N}_{2}$ during interburst periods. The respirographic technique (Sláma, 1984b; Sláma \& Denlinger, 1992; see Figs 13 and 14) made it possible to reveal that the bursts of $\mathrm{CO}_{2}$, originally described by Schneiderman and Williams in 1955 , could not be produced by the simple diffusion of $\mathrm{CO}_{2}$ from the intratracheal system into the respiratory vessel. It may be worth explaining again that a diffusional transfer of gas between different compartments of a volumetric respiratory vessel remains unrecorded. Unfortunately, Schneiderman \& Williams (1955), Buck (1956, 1962) and more recent invetigators were unaware of this common respirometric feature (cf. Lighton, 1966; Hetz \& Bradley, 2005; Chown et al., 2006; Contreras \& Bradley, 2009). Extensive use of sensitive strain-gauge techniques has revealed the presence of respiratory movements not only in Ceropia, but also in the pupae of 16 species of silkmoths (Sláma, 1991). In all cases the neuromuscular respiratory functions were actively regulated, irrespective of wheter the insect was in diapause or developing. In a small diapausing bruchid beetle (Sláma \& Coquillaud, 1992) and a number of unrelated insects and ticks (for review see Sláma, 2009; Sláma, et al., 2007), chemically produced $\mathrm{CO}_{2}$ bursts of various sizes, duration and periodicity have been recorded. The process of enzymatic hydration of carbonic acid by carbonic anhydrase is under the control of special homeostatic regulators (Sláma, 1999, 2000b; Sláma, et al., 2007).

In most insect species, the above described discontinuous exhalations of $\mathrm{CO}_{2}$ are evidently due to a bulk flow of gas, usually assisted by active ventilation (review by Sláma et al., 2007). In order to discriminate diffusional bursts of $\mathrm{CO}_{2}$ from chemically produced ones, it was proposed earlier to call the latter, chemically produced $\mathrm{CO}_{2}$ bursts, in honour of their discovery in Dytiscus by Babák (1921) as the respiratory cycles of Babák (Sláma, 1999) . 
The recordings depicted in Figs 12 to 14 reveal unequivocally that diapausing pupae of Cecropia, like numerous other insects, neutralize metabolically formed carbonic acid by the homeostatically controlled liberation of gaseous $\mathrm{CO}_{2}$ from liquid carbonate buffers. This is documented for Cecropia by the $\mathrm{CO}_{2}$ bursts shown in Figs 13 and 14. There is an instant formation of large volumes of gaseous $\mathrm{CO}_{2}$, starting qualitatively from a level of zero, with the highest rate of $\mathrm{CO}_{2}$ output at the start of the burst. The exact physiological and biochemical mechanisms involved in enzymatic hydration of carbonic acid are still unknown, due to the persistent belief in the passive diffusion of $\mathrm{CO}_{2}$ and no active regulation (review by Lighton, 1996; Chown et al., 2006). Orientation studies revealed that the physiological feedback mechanism switching the production of $\mathrm{CO}_{2}$ on and off does not depend simply on a decrease in $\mathrm{pH}$ due to the increased concentration of carbonic acid in the haemolymph. On the other hand, injections of 5 to $20 \mu \mathrm{l}$ of saturated $\mathrm{NaHCO}_{3}$ into diapausing Cecropia pupae caused a large, concentration dependent, out of schedule $\mathrm{CO}_{2}$ burst (Sláma, 2010, unpubl.). This suggests that the internal homeostatic mechanism, automatically switching the production of gaseous $\mathrm{CO}_{2}$ on and off, may depend on endogenous concentrations of carbonate ions.

Some small insects (1 to $3 \mathrm{mg}$ ) have frequent Babák type respiratory cycles, which are characaterized by relatively large bursts of $\mathrm{CO}_{2}$. Termites, for example, exhale volumes of $\mathrm{CO}_{2}$ that are greater than the volume of their whole body (Sláma, et al. 2007) within periods of less than one minute. Most respirometric investigations are based on IR- flow-through, direct recordings of $\mathrm{CO}_{2}$ output (for reviews see Lighton, 1996; Quinlan \& Gibbs, 2006; Chown et al., 2006). Unfortunately, flow-through techniques are unable to distinquish between the $\mathrm{CO}_{2}$ produced by simple diffusion and the chemical release of gaseous $\mathrm{CO}_{2}$ from carbonate buffers.

\section{Closed spiracles and low haemocoelic pressures}

Subatmospheric haemocoelic pressures are a common feature of all immobile insects (Sláma, 1991, 2003a, 2009). In contrast, the deep depressions or "hills", which are reported in the DGC as the closed spiracle phase are quite exceptional. The permanently closed spiracles (deep depressions or "hills") recorded for Cecropia in the middle of diapause (see Figs 5, 6 and 8), occur only in pupae of other saturniids, Attacus (Hetz \& Bradley, 2005), Philosamia or Saturnia (Sláma, 1991). By contrast, diapausing pupae of silkworms belonging to other families do not experience very low haemocoelic pressures and never permanently close their spiracular valves for long periods. This is the case, for example, in oak silkworms (Antheraea) or moon moths (Actias), which perform regular series of extracardiac pulsations during the whole pupal period (Sláma, 1999, 2000b, c). Theoretically, very low haemocoelic pressures can never occur in soft-bodied insects. In addition, the pupae of Cecropia never permanently close their spiracles (deep depressions) during the advanced pharate adult stages, which exhibit frequent extracardiac pulsations (Sláma, 1991).

There does not appear to be any special advantage for pupal respiration in the deep depressions with permanently sealed spiracles. The theory that oxygen is generally toxic for insects (Hetz \& Bradley, 2005; Contreras \& Bradley, 2009) also does not provide a satisfactory explanation. Evidently, the extremely low pupal demands for oxygen can be satisfied for relatively long periods of time by the air contained within the tracheal system and the large subalar cavity. The more or less random occurrence of deep depressions after $\mathrm{CO}_{2}$ bursts, in the middle of an interburst period, or only once in two or three interburst periods suggests that: (a) The closure of spiracles for a long time may be specific to diapausing pupae of saturniids or similar insects, and; (b) is not a constant feature of the discontinuous respiratory cycle.

Based on the above it is concluded that the physiological function of periods with permanently closed spiracles (deep depressions) has nothing to do with preventing oxygen toxicity. The permanently closed spiracles apparently fulfill a need other than respiratory, i.e. circulatory functions. Cecropia pupae have long appendages, legs, antennae and palpi, which lack special pulsatory organs. The circulation induced by the heartbeat does not reach these structures. The deep decrease in internal pressure causes a temporary outflow of haemolymph from the elastic integumental structures or appendages into the main haemocoelic cavity. The central septum and tissue folds also function as passive, unidirectional valves returning the haemolymph flow back into the appendages when the pressure increases again (see Sláma, 2009 for a review). A simple circulatory adaptation in the form of deep depressions can thus effectively substitute for the circulatory role of haemocoelic pulsations in preventing the death of appendages during diapause.

Physiological conditions associated with passive inspirations (saw-tooth pattern) are complex. This feature of precisely determined periods of intermittent inspirations through carefully selected spiracles does not occur in post diapause, developing pupae of Cecropia, which show a more or less continuous production of $\mathrm{CO}_{2}$ and frequent ventilatory movements. It also does not occur in insects metabolizing predominantly carbohydrate, which produce equal amounts or more $\mathrm{CO}_{2}$ than of $\mathrm{O}_{2}$ consumed (ants, aphids, termites, fruitflies; Sláma, 1960, 1988, 1999; Sláma \& Neven, 2001; Sláma et al., 2007). Analysis of the recordings in Figs 2, 3, 5-9 and also the respirographic recordings in Figs 13 and 14 (plus dozens of recordings not presented here), reveals several physiological characteristics of the passive inspirations; (1) The spiracular valves are permanently closed during the deep depressions ("hills"); (2) During a major part of the interburst period (saw-tooth pattern), the usual periodicity of the snapping open of the valves is 1 to $3 \mathrm{~min}$ (at room temperature); (3) The snapping opening of the valves, which is under neuromuscular control, results in a large inflow of air into the body; (4) The velocity and volume of the air intake, which can last less than $350 \mathrm{~ms}$, are 
directly proportional to the degree of the internal subatmospheric vacuum; (5) The convective large flow of air through the narrow apertures of individual spiracular valves proceeds while the negative pressure gradient is between 0.5 and $5 \mathrm{kPa}$; (6) The speed of the internally directed flow is fast enough to eliminate a countercurrent of diffusion or escape of water vapour during the interburst period; (7) Formation of the internal vacuum is enhanced almost three fold (ratio of $\mathrm{CO}_{2} / \mathrm{O}_{2}=0.7$ ) by the retention of $\mathrm{CO}_{2}$ in liquid carbonate buffers (review by Sláma, 2009).

The sub-atmospheric levels of haemocoelic pressure, passive inspirations and twisting movements were recorded 20 years ago in pupae of 16 species of bombycoid and saturniid species (Sláma, 1991). Independent of whether they were in diapause or developing the pupae of all these species performed large abdominal movements in the form of: (a) sudden longitudinal abdominal contractions (pumping movements); (b) occasional rotations of the abdomen, or (c) occasional twitching of the abdominal tail from one side to the other. These movements occurred at constant intervals from just once in a few minutes (developing pupae) to once in 16 or more hours (diapausing pupae). Many years ago, in 1990, I discussed the best term for these movements with the late Prof. V.B. Wigglesworth. He wrote: "Twisting movements might be useful to you (one twists and turns in one's sleep). Wriggling implies a more active movementas in trying to escape after being seized" (see Sláma, 1991). The twisting movements are very important for maintaining homeostatic physiological functions in an immobile pupal body. They produce large pulses in haemocoelic pressure (up to $5 \mathrm{kPa}$ difference from positive to negative values) when spiracular valves are closed, or produce a relatively large, unidirectional tracheal ventilation when certain spiracular valves alternatively open and close. The large twisting movements exhibited by pupae of Cecropia during the closed spiracle phase had no ventilatory consequences (see Fig. 8), in spite of large changes in internal pressure. In this case, large surges in haemocoelic pressure caused by the twisting movements would certainly promote circulation, especially of haemolymph through the appendages. They could act as dynamic pressure pumps, like the deep depressions and large intakes of air.

Authors studying the respiratory cycles (DGC) in other insects often assume rather long periods of permanently closed spiracles, without realizing that this feature might be specific for diapausing pupae of Cecropia and could never occur in insects with relatively high metabolic rates (Miller, 1981; Kestler, 1985; Lighton, 1996; Wasserthal, 1996; Hetz \& Bradley, 2005; Qinlan \& Gibbs, 2006; Chown et al., 2006; Klowden, 2007). Closing spiracles for long periods (several minutes of DGC, closed spiracle phase) is unrealistic, especially for adult ants, beetles or flies. Evidence for this comes from a simple experiment in which the spiracles are closed by submerging an insect in water. When submerged for less than one tenth of the period (1 to $3 \mathrm{~min}$ ) for which the spiracles are closed during the DGC, adult insects fall into a deep narcosis associated with prolonged paralysis of all neuromuscular functions. On the other hand, diapausing Cecropia pupae survive submersion in water for many hours or several days. This shows that the results from studies on diapausing pupae cannot be automatically applied to other insects. In addition, there is no reason why the discontinuous respiration cycle of diapausing Cecropia should be applied to diapausing stages of other insects. Simultaneously with the description of DGC in Cecropia by Schneiderman (1960), there appeared descriptions of continuous respiratory metabolism, without discontinuous bursts of $\mathrm{CO}_{2}$, in diapausing larval stages of sawflies (Sláma, 1960). These findings remained unnoticed in the shadow of the work on Cecropia.

\section{Fluttering spiracles and extracardiac pulsations}

Perhaps the greatest confusion in the interpretation of discontinuous respiration in insects was that over the role of the mysterious "fluttering" of the spiracular valves. Schneiderman (1960) originally described this phenomenon as the intermittent opening and closure of spiracular valves with a periodicity of 15 to 22 per minute. This was exactly what he observed when looking inside spiracles after removal of external cuticular sieves. Curiously enough, the "fluttering" occurred only in certain pupae, at certain periods, especially in pupae restrained for various experimental manipulations. It was assumed, nevertheless, that this spiracular "fluttering" might constitute a part of the discontinuous respiration cycle, occuring especially during the period when $\mathrm{CO}_{2}$ accumulates before each burst (Levy \& Schneiderman, 1966a, b, c). This assumption actually led to the concept of DGC respiration cycles, composed of periods of open, closed and "fluttering" spiracles. Later on, the stereotypic DGC concept, elaborated originally for giant diapausing pupae with the lowest metabolic rates, was uncritically applied to insects with the highest metabolic rates, i.e. ants, which show up to 1000-fold higher rates of gaseous exchange than Cecropia (review by Lighton, 1996).

The original definition of spiracle "fluttering" by Schneiderman and his colleagues did not consider the possibility of active ventilatory movements. In agreement with Krogh's theory (1920), they denied the existence of such movements in Cecropia until 1967 (see Brockway \& Schneiderman, 1967). The results presented here clearly show that the mysterious spiracular "fluttering" is intimately associated with extracardiac pulsations in haemocoelic pressure, whose ventilatory function was discovered much later (Sláma, 1976).

The extracardiac pulsations recorded (see Figs 1, 6, 9-12) reveal that the frequency and amplitude correspond exactly with that cited in the original descriptions of "fluttering" by Schneiderman (1960). According to the microanemometric results presented earlier (Sláma, 1988, 1999), the spiracular valves of Cecropia pupae twinkle or pulsate in synchrony with extracardiac pulsations, whose ventilatory functions are under the control of an autonomic neuroendocrine system (review by Sláma, 2009). According to recent observations on various insect spe- 
cies (Sláma, 2009), extracardiac pulsations or "fluttering" of the spiracles are by no means a constant part of the discontinuous respiration cycles. Even in diapausing Cecropia, the feature is limited to $\mathrm{CO}_{2}$ bursts or may be absent. Obviously, these results conflict with the standard interpretation of discontinuous respiration cycles (DGC), which traditionally place the periods of "fluttering" where they can never occur (Lighton, 1996; Quinlan \& Gibbs, 2006).

Schneiderman's hesitations with respect to spiracular "fluttering" and DGC were apparently related to Krogh's (1920) diffusion theory, which ignored previously accumulated information on ventilatory movements in insects (rev. by Babák, 1921). In 1966, Levy \& Schneiderman (1966c) still conclude that: "...pupae of Hyalophora cecropia have no respiratory movements except those of the spiracular valves". Almost simultaneously, however, they changed their mind and discovered: “...existence of respiratory movements which have heretofore been unsuspected" (Schneiderman \& Schechter, 1966). Finally, Brockway \& Schneiderman (1967) describe the ventilatory movements as rhythmically repeated movements of the abdomen, which Babák (1921) and Kuznetzoff (1953) beautifully described earlier in numerous species of insects and ticks. It is important to cite in detail some original papers, because there are serious misinterpretations in the literature by some authors who cannot have read the original papers.

It appears that all insects need ventilatory movements that prevent respiratory acidaemia and desiccation (Sláma, 1988, 1999; review by Sláma, 2009). There are many spiracles on an insect's body, even those smaller than one $\mathrm{mm}$. Their internal valves are maximally constricted (Jordan, 1927) and the access of tracheal space to outside air is usually filtered by spiracular atria and external cuticular sieves (Babák, 1921). These anatomical and physiological adaptations have evidently evolved to reduce the diffusional escape of water from the body. This explains why most insects need to use ventilatory movements, like humans; otherwise they suffocate and die (Sláma et al., 2007). In the miniature pupa of the leekmoth, for example, the repeated series of ventilatory movements are in the range of nanometers (Sláma \& Coquillaud, 1992). Due to their relatively small amplitudes, these ventilatory movements remained unnoticed, even those of large pupae, or confused with the heartbeat (cf. Wassserthal, 1996). Recently, respiratory movements in the range of a few nanometers were recorded in insects as small as adult fruit flies, Drosophila melanogaster (Sláma, 2010).

Abdominal movements associated with extracardiac ventilatory pulsations in Cecropia (Figs 1, 6, 9 to 12) are also relatively small. The movements of air are caused by an "abdominal pressure pump", which is operated by coordinated neuromuscular contractions of large intersegmental abdominal muscles. The ventilatory movements, monitored from the end of flexible abdominal segments (4 to 7 ), are as small as $2.5 \mu \mathrm{m}$, i.e. only $1 / 1600$ th of the pupal length (Fig. 9). The large abdominal pulsation in
Fig. 10 has also a relatively small amplitude of about 10 $\mu \mathrm{m}$ (1/400th of the pupal length). It is obvious that Krogh (1920), Schneiderman (1960), Wasserthal (1996) and Lighton (1996) did not have adequate techniques for visualizing these minute pulsations.

In spite of their relatively small size, extracardiac pulsations in haemocoelic pressure have a rather large effect on the convective ventilation of intratracheal space. In Fig. 10 , for example, the pulsation has a frequency of 22 pulses per minute with an amplitude of $10 \mu \mathrm{m}$ per pulse. Assuming a $14 \mathrm{~mm}$ diameter of the medium retracting (6th) abdominal segment it has a $154 \mathrm{~mm}^{2}$ of cross section area, and therefore the rate of the unidirectional tracheal ventilation will be $34 \mu \mathrm{l}$ of air per minute. This rate of air flow is sufficient to exchange most of the tracheal space within some 10 or $15 \mathrm{~min}$. The direct effects of extracardiac pulsation on the passage of air through 8 simultaneously recorded spiracles was earlier described for diapausing pupae of Cecropia by Sláma (1988). This type of advanced monitoring of inspirations and expirations through multiple spiracles was achieved by using a novel, microanemometric technique for recording the passage of air through multiple spiracles. Extracardiac haemocoelic pulations are used for tracheal ventilation not only by giant pupae of Hyalophora or Attacus. They are recorded in the developing or diapausing pupae of other insect species (Sláma, 2000a, 2009), sometimes as small as those of the codling moth (Sláma \& Neven, 2001).

Unaware of the existence of extracardiac haemocoelic pulsations discovered later by Sláma in 1976, certain authors record cumbersome "vibrations" (Hazelhoff in Periplaneta; see Jordan, 1927) or "fluttering" of spiracular valves (Hyalophora; Schneiderman, 1960). The "fluttering" behaviour of spiracular valves is indeed quite confusing, because the old theoretical concepts only regarded the mechanical opening or closure of spiracular valves to depend on the internal or external composition of gases. The concept was perhaps best characterized by Schneiderman \& Schechter (1966) "The periodic release of carbon dioxide is caused by periodic movements of the spiracular valves. These movements are triggered by the changing composition of the tracheal gas: high tracheal $\mathrm{pCO}_{2}$ causes the spiracles to open, low tracheal $\mathrm{pO}_{2}$ causes them to flutter, high tracheal $\mathrm{pO}_{2}$ causes them to constrict". This mechanistic explanation ignores the neuromotoric innervation and function of the spiracular muscles, which was described and reviewed by Babák as early as 1921. The innervation and functions of the pupal spiracular valves in Cecropia were rediscovered much later (Burkett \& Schneiderman, 1974a, b).

Recent electrophysiological studies show that insect spiracular valves actually pulsate, twinkle, flash, snap open, or simply move at millisecond intervals, in precise coordination with the individual strokes of the abdominal pressure pump (Sláma, 1988, 1999). This neuroendocrine regulated accordion- or bellows-like insect breathing results in very efficient, unidirectional ventilation of the tracheal system (review by Sláma, 2009). Neuroendocrine coupling of the spiracular opening with pumping move- 
ments of abdominal somatic muscles is important physiological function of the autonomic nervous system of insects (coelopulse).

Diapausing pupae of Cecropia need very little oxygen (7-25 $\mu \mathrm{l} \mathrm{O}_{2} / \mathrm{g} / \mathrm{h}$ at room temp.; see also Schneiderman \& Williams, 1955). Spiracular valves can thus remain tightly closed for several hours as sufficient oxygen remains within the body to meet the very low respiratory demands of tissues and organs. Hence, the gas in the tracheal system is rarely exchanged and only during the periods of $\mathrm{CO}_{2}$ bursts. There is no need for extracardiac ventilatory pulsations except to enhance the ventilation of $\mathrm{CO}_{2}$ during the burst. Similar timing of extracardiac haemocoelic pulsations within the $\mathrm{CO}_{2}$ bursts is described for diapausing pupae of Attacus atlas (Sláma, 1999) and Manduca sexta (Sláma, 2003). The very low metabolic demands for oxygen of diapausing pupae inspired some authors to speculate about the general toxicity of oxygen for insects (Hetz \& Bradley, 2005; Contreras \& Bradley, 2009).

The recordings in Figs 2 to 8 show that the spiracular valves of diapausing Cecropia pupae remain closed for almost the whole of the interburst period. The internal vaccum that develops (due to $\mathrm{O}_{2}$ consumption) is periodically reduced by the snap-opening of only one or just a few, selected spiracular valves. Obviously, this function can be effective only when the neuromuscular apparatus of all the spiracular valves is controllable and all valves can be tightly closed. If only one of the valves is defective, the chances of a pupa surviving overwinter will be substantially reduced. In this case, the essential attributes of discontinuous respiration, such as the deep depressions ("hills") and passive suction inspirations (saw tooth pattern) could not occur and the pupa would sooner or later die of desiccation. Under these circumstances, air will constantly flow into the body through the defective spiracle. In order to overcome this handicap, the pupa will have to make vigorous extracardiac ventilatory pulsations. Retrospectively, it is possible to conclude that a defective spiracle was probably responsible for the discovery of spiracular "fluttering" during the interburst periods in pupae with open or cannulated spiracles (Schneiderman, 1960; Levy \& Schneiderman, 1958, 1966a).

The physiological role of spiracular "fluttering" was unknown before the discovery of extracardiac haemocoelic pulsations. Brockway \& Schneiderman (1967) found active ventilatory movements with frequencies identical to the previously described "fluttering" of the spiracles (16-22/min). They did not indicate whether there was a causal relationship between the two, but suddenly changed their original interpretation of "fluttering" (frequency $16-22 / \mathrm{min}$ ) to that of an individual snapopening of the valves during passive inspirations (sawtooth pattern in the recordings presented here). The confusing new definition was: "The flutter period consists of a series of microcycles each of which is caused by a brief valve opening followed by a much longer valve closure. It occupies 60 to 90 per cent of the respiratory cycle" (Brockway \& Schneiderman, 1967). This definition of spiracle "fluttering" subsequently caused a lot of misunderstanding and confusion. Since then, the term of spiracular "fluttering" has been used to explain diverse, often imaginary or nonexisting parts of the DGC. In most cases, these judgements were made without knowing anything about the behaviour of the spiracular valves (reviews by Kestler, 1985; Lighton, 1996; Wasserthal, 1996; Chown et al., 2006; Contreras \& Bradley, 2009).

The final conclusion of this study is that the discontinuous respiration cycle of diapausing pupae of Cecropia may be more simple than that predicted by the persistent myths about the mechanical DGC. The metabolically produced carbonic acid is retained within the haemolymph or tissues until the time of the homeostatically regulated outburst of gaseous $\mathrm{CO}_{2}$ from the liquid carbonate buffers. During the several hour-long interburst periods, the spiracular valves can be kept tightly closed in order to prevent water loss as the demands for oxygen are very low. An internal vacuum, which is constantly created due $\mathrm{O}_{2}$ consumption, is homeostatically regulated by the snapopening, once per 1 to $3 \mathrm{~min}$ (at room temperature). of alternating spiracular valves. The sudden increase in chemically produced gaseous $\mathrm{CO}_{2}$ during the burst is actively ventilated by extracardiac pulsations in haemocoelic pressure, which cause a coordinated pulsation of the spiracular valves (originally described as spiracular "fluttering"). This active homeostatic regulation of discontinuous respiration in insects is an excellent example of the operation of the recently discovered, autonomic, cholinergic, neuroendocrine system of insects (coelopulse), which is analogous to the parasympathetic cholinergic system of vertebrates (review by Sláma, 2009).

ACKNOWLEDGEMENT. I am indebted to S. Phillips of Portland, Oregon, for correcting the English text.

\section{REFERENCES}

BABÁK E. 1921: Die Mechanik und Innervation der Atmung. D. Tracheaten. In Winterstein H. (ed.): Handbuch der Vergleichenden Physiologie. Gustav Fischer, Jena, pp. 265-1052.

BrockwAy A.F. \& SChNeIDERMAn H.A. 1967: Strain-gauge transducer studies on intratracheal pressure and pupal length during discontinuous respiration in diapausing silkworm pupae. J. Insect Physiol. 13: 1413-1451.

BucK J.B. 1956: Possible mechanism and rationale of cyclic $\mathrm{CO}_{2}$ retention by insects. Proc. 10th Int. Congr. Entomol. 2: 339-342.

Buck J.B. 1962: Some physical aspects of insect respiration. Annu. Rev. Entomol. 7: 27-56.

Burkett B.N. \& Schneiderman H.A. 1974a: Roles of oxygen and carbon dioxide in the control of spiracular function in cecropia pupae. Biol. Bull. 147: 274-293.

Burkett B.N. \& Schneiderman H.A. 1974b: Discontinuous respiration in insects at low temperatures: Intratracheal pressure changes and spiracular valve behavior. Biol. Bull. 147: 294-310.

Chown S.L., Gibbs A.G., Hetz S.K., Klok G.J., Lighton J.R.B. \& Marais E. 2006: Discontinuous gas exchange in insects: A clarification of hypotheses and approaches. Physiol. Biochem. Zool. 79: 333-343. 
Contreras H.L. \& Bradley T.J. 2009: Metabolic rate controls respiratory pattern in insects. J. Exp. Biol. 212: 424-428.

Hetz S.K. \& Bradley T.J. 2005: Insects breathe discontinuously to avoid oxygen toxicity. Nature 433: 516-519.

JORDAN H. 1927: Die Regulierung der Atmung bei Insekten und Spinnen. Z. Vergleich. Physiol. 5: 179-190.

KESTLER P. 1985: Respiration and respiratory water loss. In Hoffmann K.H. (ed.): Environmental Physiology and Biochemistry of Insects. Springer, Berlin, Heidelberg, pp. 137-183.

Klowden M.J. 2007: Physiological Systems in Insects. 2nd ed. Elsevier, Amsterdam, $688 \mathrm{pp}$

KROGH A. 1920: Studien über Tracheenrespiration. II. Über Gasdiffusion in den Tracheen. Pflüger's Arch. Ges. Physiol. 179: 95-112.

Kuznetzoff N.YA. 1953: The Principles of Insect Physiology. Vol. 2. Izdatelstvo Akademii Nauk SSSR, Moscow, Leningrad, 402 pp. [in Russian].

LEVy R.I. \& SChNEIDERMan H.A. 1958: An experimental solution to the paradox of discontinuous respiration in insects. Nature 182: 491-493.

Levy R.I. \& SchneIDERMAn H.A. 1966a: Discontinuous respiration in insects II. The direct measurementand significance of changes in tracheal gas composition during the respiratory cycle of silkworm pupae. J. Insect Physiol. 12: 83-104.

LeVy R.I. \& SchneIDERMAn H.A. 1966b: Discontinuous respiration in insects III. The effect of temperature and ambient osygen tension on the gaseous composition of the tracheal system of silkworm pupae. J. Insect Physiol. 12: 105-121.

LEVY R.I. \& SCHNEIDERMAN H.A. 1966c: Discontinuous respiration in insects IV. Changes in intratracheal pressure during the respiratory cycle of silkworm pupae. J. Insect Physiol. 12: 465-492.

Lighton J.R.B. 1996: Discontinuous gas exchange in insects. Annu. Rev. Entomol. 41: 309-324.

MiLLER P.L. 1981: Ventilation in active and inactive insects. In F.C. Herreid \& Fourtner C.R. (eds): Locomotion and Energetics in Arthropods. Plenum, New York, London, pp. $367-390$

Nation J.L. 2002: Insect Physiology and Biochemistry. CRC Press, Boca Raton, 485 pp.

Quinlan M.C. \& GibBs A.G. 2006: Discontinuous gas exchange in terrestrial insects. Resp. Physiol. Neurobiol. 154: 18-29.

SChNEIDERMAn H.A. 1956: Spiracular control of discontinuous respiration in insects. Nature 177: 1169-1171.

SCHNEIDERMAN H.A. 1960: Discontinuous respiration in insectrs: role of the spiracles. Biol. Bull. 119: 494-528.

SchneIderman H.A. \& Schechter A.N. 1966: Discontinuous respiration in insects V. Pressure and volume changes in the tracheal system of silkworm pupae. J. Insect Physiol. 12: $1143-1170$.

Schneiderman H.A. \& Williams C.M. 1955: An experimental analysis of the discontinuous respiration of the cecropia silkworm. Biol. Bull. 109: 123-143.

Sláma K. 1960: Physiology of sawfly metamorphosis. I. Continuous respiration in diapausing prepupae and pupae. $J$. Insect Physiol. 5: 341-348.
SLÁmA K. 1976: Insect haemolymph pressure and its determination. Acta Entomol. Bohemoslov. 73: 65-75.

Sláma K. 1984a: Recording of haemolymph pressure pulsations from the insect body surface. J. Comp. Physiol. (B) 154: 635-643.

Sláma K. 1984b: Microrespirometry in small tissues and organs. In Bradley T.J. \& Miller T.A. (eds): Measurement of Ion Transport and Metabolic Rate in Insects. Springer, New York, Berlin, pp. 103-129.

SlÁmA K. 1988: A new look at insect respiration. Biol. Bull. 175: $289-300$.

SLÁMA K. 1991: Regulation of autonomic physiological functions in silkmoths. In Akai H. \& Kiuchi M. (eds): Wild Silkmoths. Int. Soc. Wild Silkmoths, Tsukuba, pp. 107-119.

SLÁmA K. 1994: Regulation of respiratory acidemia by the autonomic nervous system (Coelopulse) in insects and ticks. Physiol. Zool. 67: 163-174.

SlÁmA K. 1999: Active regulation of insect respiration. Ann. Entomol. Soc. Am. 92: 916-929.

SlÁmA K. 2000a: Extracardiac versus cardiac haemocoelic pulsations in pupae of the mealworm (Tenebrio molitor L.). $J$. Insect Physiol. 46: 977-992.

SLÁMA K. 2000b: A new look at insect breathing. In: Procedings of XXI International Congress of Entomology. Vol. 1. Foz do Iguassu, Brazil, pp. 33-38.

SlÁmA K. 2000c: Recording of spiracular functions by artificially generated pressure pulses. In: Procedings of XXI International Congress of Entomology. Vol. 1. Foz do Iguassu, Brazil, p. 3087.

SlÁmA K. 2003: Mechanical aspects of heartbeat reversal in pupae of Manduca sexta. J. Insect Physiol. 49: 645-657.

SLÁMA K. 2009: Extracardiac haemocoelic pulsations and the autonomic neuroendocrine system (coelopulse) of terrestrial insects. Terrestr. Arthrop. Rev. 1: 39- 80.

SLÁmA K. 2010: Physiology of heartbeat reversal in adult Drosophila melanogaster (Diptera: Drosophilidae). Eur. J. Entomol. 107: $13-31$.

SlÁma K. \& Coquillaud M.-S. 1992: Homeostatic control of respiratory metabolism in beetles. J. Insect Physiol. 38: 783-791.

SlÁma K. \& Denlinger D.L. 1992: Infradian cycles of oxygen consumption in diapausing pupae of the flesh fly, Sarcophaga crassipalpis, monitored by a scanning microrespirographic method. Arch. Insect Biochem. Physiol. 20: 135-143.

Sláma K. \& Neven L. 2001: Active regulation of respiration and circulation in pupae of the codling moth (Cydia pomonella). J. Insect Physiol. 47: 1321-1336.

SLÁmA K., ŠobotNíK J. \& Hanus R. 2007: Respiratory concerts revealed by scanning microrespirography in termite (Prorhinotermes simplex). J. Insect Physiol. 53: 295-311.

WASSERTHAL L.T. 1996: Interaction of circulation and tracheal ventilation in holometabolous insects. Adv. Insect Physiol. 25: 297-351.

Wigglesworth V.B. 1965: The Principles of Insect Physiology. 6th ed. Methuen, London, New York, 741 pp.

Received April 21, 2010; revised and accepted June 7, 2010 